\title{
Evolution of $\mathrm{OH}$ reactivity in NO-free volatile organic compound photooxidation investigated by the fully explicit GECKO-A model
}

\author{
Zhe Peng ${ }^{1,2}$, Julia Lee-Taylor ${ }^{1,2,3}$, Harald Stark ${ }^{1,2,4}$, John J. Orlando ${ }^{3}$, Bernard Aumont ${ }^{5}$, and Jose L. Jimenez ${ }^{1,2}$ \\ ${ }^{1}$ Department of Chemistry, University of Colorado Boulder, Boulder, Colorado 80309, USA \\ ${ }^{2}$ Cooperative Institute for Research in Environmental Sciences, University of Colorado Boulder, \\ Boulder, Colorado 80309, USA \\ ${ }^{3}$ Atmospheric Chemistry Observation and Modeling Laboratory, National Center for Atmospheric Research, \\ Boulder, Colorado 80307, USA \\ ${ }^{4}$ Aerodyne Research Inc., Billerica, Massachusetts 01821, USA \\ ${ }^{5}$ Univ. Paris Est Créteil and Université de Paris, CNRS, LISA, 94010 Créteil, France
}

Correspondence: Zhe Peng (zhe.peng@ colorado.edu) and Jose L. Jimenez (jose.jimenez@ colorado.edu)

Received: 10 February 2021 - Discussion started: 24 February 2021

Revised: 7 August 2021 - Accepted: 10 September 2021 - Published: 4 October 2021

\begin{abstract}
OH reactivity (OHR) is an important control on the oxidative capacity in the atmosphere but remains poorly constrained in many environments, such as remote, rural, and urban atmospheres, as well as laboratory experiment setups under low-NO conditions. For an improved understanding of OHR, its evolution during oxidation of volatile organic compounds (VOCs) is a major aspect requiring better quantification. We use the fully explicit Generator of Explicit Chemistry and Kinetics of Organics in the Atmosphere (GECKOA) model to study the OHR evolution in the NO-free photooxidation of several VOCs, including decane (an alkane), $m$-xylene (an aromatic), and isoprene (an alkene). Oxidation progressively produces more saturated and functionalized species. Total organic OHR (including precursor and products, OHR ${ }_{V O C}$ ) first increases for decane (as functionalization increases $\mathrm{OH}$ rate coefficients) and $m$-xylene (as much more reactive oxygenated alkenes are formed). For isoprene, $\mathrm{C}=\mathrm{C}$ bond consumption leads to a rapid drop in $\mathrm{OHR}_{\mathrm{VOC}}$ before significant production of the first main saturated multifunctional product, i.e., isoprene epoxydiol. The saturated multifunctional species in the oxidation of different precursors have similar average $\mathrm{OHR}_{\text {VOC }}$ per $\mathrm{C}$ atom. The latter oxidation follows a similar course for different precursors, involving fragmentation of multifunctional species to eventual oxidation of $\mathrm{C} 1$ and $\mathrm{C} 2$ fragments to $\mathrm{CO}_{2}$, leading to a similar evolution of OHR ${ }_{\mathrm{VOC}}$ per $\mathrm{C}$ atom. An upper limit of the total $\mathrm{OH}$ consumption during complete oxidation to $\mathrm{CO}_{2}$
\end{abstract}

is roughly three per $\mathrm{C}$ atom. We also explore the trends in radical recycling ratios. We show that differences in the evolution of OHR VOC between the atmosphere and an environmental chamber, and between the atmosphere and an oxidation flow reactor (OFR), can be substantial, with the former being even larger, but these differences are often smaller than between precursors. The Teflon wall losses of oxygenated VOCs in chambers result in large deviations of OHR ${ }_{V O C}$ from atmospheric conditions, especially for the oxidation of larger precursors, where multifunctional species may suffer substantial wall losses, resulting in significant underestimation of OHR VOC. For OFR, the deviations of OHR VOC evolution from the atmospheric case are mainly due to significant OHR contribution from $\mathrm{RO}_{2}$ and lack of efficient organic photolysis. The former can be avoided by lowering the UV lamp setting in OFR, while the latter is shown to be very difficult to avoid. However, the former may significantly offset the slowdown in fragmentation of multifunctional species due to lack of efficient organic photolysis.

\section{Introduction}

Photooxidation is a key process altering the concentrations of trace gases in the atmosphere (Levy II, 1971; Atkinson and Arey, 2003). It is also the main contributor to the formation of $\mathrm{O}_{3}$ and secondary aerosols (Haagen-Smit, 1952; Chameides 
et al., 1988; Hallquist et al., 2009). Both products are major tropospheric pollutants (Nel, 2005; Cohen et al., 2017), and the latter have large climate impacts (Stocker et al., 2014).

Hydroxyl radical $(\mathrm{OH})$ is the primary oxidizing agent in atmospheric photooxidation (Levy II, 1971). Its atmospheric fate is governed by the species that it reacts with, i.e., $\mathrm{OH}$ reactants. The first-order rate constant of $\mathrm{OH}$ consumption by an $\mathrm{OH}$ reactant is often called its $\mathrm{OH}$ reactivity (OHR), equal to the product of the reactant concentration and secondorder rate constant with $\mathrm{OH}$. Total $\mathrm{OHR}\left(\mathrm{OHR}_{\text {tot }}\right)$, i.e., the sum of OHR across all $\mathrm{OH}$ reactants $\left(\mathrm{OHR}_{\mathrm{tot}}=\sum_{i}\left(k_{i} \cdot c_{i}\right)\right.$, where $k_{i}$ and $c_{i}$ are the second-order rate constant with $\mathrm{OH}$ and concentration of the $i$ th $\mathrm{OH}$ reactant), is the real firstorder loss rate constant of $\mathrm{OH}$.

OHR has been measured for over 20 years (Kovacs and Brune, 2001) in various settings, e.g., urban areas ( $\mathrm{Lu}$ et al., 2013; Whalley et al., 2016), forested areas (Nölscher et al., 2016; Zannoni et al., 2016), and environmental chambers (Fuchs et al., 2013, 2017; Nölscher et al., 2014; Novelli et al., 2018). Despite numerous measurements and remarkable technical developments (Yang et al., 2016; Fuchs et al., 2017), a sizable fraction of total OHR in most measurements has not been chemically speciated, leading to so-called "missing reactivity" (Williams and Brune, 2015; Yang et al., 2016). Multiple studies (Nölscher et al., 2016; Whalley et al., 2016; Sato et al., 2017) have attributed missing reactivity to the highly complex mixture of intermediates and products of volatile organic compound (VOC) oxidation, most of which are oxygenated VOCs (OVOCs). Primary VOCs themselves have been found to be the largest contributor of the speciated OHR in many studies (Yang et al., 2016). In order to well understand ambient OHR, the evolution of OHR (including that from OVOCs) during primary VOC photooxidation thus needs to be investigated.

Experimentally, this can be done in environmental chambers. However, only a few such experiments have been published (Nakashima et al., 2012; Nehr et al., 2014; Nölscher et al., 2014; Sato et al., 2017), all under high-NO conditions, where the key organic radical intermediate in VOC oxidation, i.e., organic peroxy radical $\left(\mathrm{RO}_{2}\right)$, mainly reacts with NO. To our knowledge, no experiment of this type at low $\mathrm{NO}$, where $\mathrm{RO}_{2}$ can substantially react with hydroperoxy radical $\left(\mathrm{HO}_{2}\right)$, has been published so far, potentially partially due to the difficulty in experimentally ensuring that low-NO conditions are achieved in chambers (Nguyen et al., 2014). Also, many OVOCs, which may account for missing reactivity, have sufficiently low volatility to significantly partition to chamber walls (Matsunaga and Ziemann, 2010; Krechmer et al., 2016), further complicating these experiments. The OVOC wall losses also often limit operation times of chamber experiments to a few hours, after which the wall losses are so large that meaningful interpretation of experimental results would be difficult. Therefore, the highest equivalent photochemical age that can be reached in chamber experiments is also typically hours and far shorter than would be needed to explore the OHR evolution in later stages of VOC oxidation.

Oxidation flow reactors (OFR) are an alternative to chambers with much smaller volume, shorter residence time (and thus smaller wall losses of trace gases), and stronger oxidative capacity (Kang et al., 2007; Brune, 2019; Peng and Jimenez, 2020). The most common version of OFR is equipped with low-pressure $\mathrm{Hg}$ lamps emitting $\mathrm{UV}$ at 185 and $254 \mathrm{~nm}$, which photolyzes water vapor, $\mathrm{O}_{2}$, and $\mathrm{O}_{3}$ and generates a large amount of $\mathrm{OH}$ both directly and through subsequent radical reactions. High $\mathrm{OH}$ concentration in OFR often leads to equivalent photochemical age of days to weeks (Li et al., 2015; Peng et al., 2015). In principle, OFR can also be employed to explore OHR evolution in VOC oxidation. However, OHR from VOC (OHR ${ }_{V O C}$, from both precursor and oxidation intermediates/products, in which we include $\mathrm{CO}$ as an "organic" product of VOC oxidation) can have strong impacts on oxidative capacity (particularly $\mathrm{OH}$ concentration) and hence radical chemistry in OFR at both low (Li et al., 2015; Peng et al., 2015) and high NO (Peng and Jimenez, 2017; Peng et al., 2018). Peng and Jimenez (2020) have called for highly chemically detailed modeling of gasphase organic chemistry in OFR to assess the impacts of organic $\mathrm{OH}$ reactants on $\mathrm{OH}$ in a more quantitative manner.

In this study, we explore for the first time the OHR evolution in entire NO-free VOC photooxidation processes by modeling. Since chemical mechanism incompleteness causes other models to unsatisfactorily simulate measured $\mathrm{OHR}_{\text {tot }}$ (Williams and Brune, 2015), we use the fully chemically explicit model GECKO-A (Generator of Explicit Chemistry and Kinetics of Organics in the Atmosphere) (Aumont et al., 2005). We simulate the photooxidation of different types of VOCs in the atmosphere, in chamber, and in OFR to find out general trends of OHR evolution in VOC oxidation and whether VOC oxidation chemistries in chamber and OFR are representative of that in the atmosphere in terms of OHR evolution.

\section{Methods}

Here we first discuss the VOC precursor types and conditions selected for the model cases in this study. Then we describe the GECKO-A model and present our additional mechanism, model, and software development required for this study.

\subsection{Model cases}

The photooxidation of an alkane (decane), an alkene (isoprene), and an aromatic ( $m$-xylene) is investigated under a variety of conditions without any NO. In pristine regions such as open oceans, NO has typical concentrations on the order of $1 \mathrm{ppt}$ (Wofsy et al., 2021) and hence contributes only a few percent to $\mathrm{RO}_{2}$ loss (Peng et al., 2019). For simplicity, we choose not to maintain such a low NO level in the simu- 
Table 1. Conditions and integration time steps of the simulations in the present work.

\begin{tabular}{|c|c|c|c|c|c|}
\hline Precursor & Environment & $\begin{array}{l}\text { Relative } \\
\text { humidity }(\%)\end{array}$ & UV & $\begin{array}{l}\text { Initial } \mathrm{OH} \\
\text { reactivity }\left(\mathrm{s}^{-1}\right)\end{array}$ & Integration time step (s) \\
\hline \multirow[t]{2}{*}{ Methane } & Ambient & 30 & Constant sunlight $^{\mathrm{a}}$ & \multirow[t]{2}{*}{10} & \multirow[t]{2}{*}{ KinSim-determined $^{\mathrm{b}}$} \\
\hline & Oxidation flow reactor & 70 & High lamp setting ${ }^{c}$ & & \\
\hline \multirow[t]{13}{*}{ Decane } & \multirow[t]{2}{*}{ Ambient } & \multirow[t]{2}{*}{30} & Constant sunlight $^{\mathrm{a}}$ & \multirow[t]{2}{*}{10} & \multirow[t]{2}{*}{ Min: $0.1 ; \max : 120(1 \mathrm{~d}), 300(2-10 \mathrm{~d})$} \\
\hline & & & Diurnal sunlight & & \\
\hline & \multirow[t]{5}{*}{ Oxidation flow reactor } & 70 & High lamp setting ${ }^{c}$ & 10 & \multirow[t]{5}{*}{0.0025} \\
\hline & & 70 & Low lamp setting $\mathrm{e}$ & 10 & \\
\hline & & 30 & Medium lamp setting $\mathrm{f}$ & 10 & \\
\hline & & 3 & High lamp setting ${ }^{c}$ & 10 & \\
\hline & & 70 & High lamp setting ${ }^{c}$ & 1000 & \\
\hline & \multirow[t]{2}{*}{ Chamber (gas-phase only) } & \multirow[t]{6}{*}{30} & \multirow[t]{6}{*}{ CU chamber spectrum ${ }^{\mathrm{g}}$} & 10 & \multirow[t]{6}{*}{ Min: $0.1 ; \max : 120(6 \mathrm{~d}), 300(7-30 \mathrm{~d}$ if needed $)$} \\
\hline & & & & 100 & \\
\hline & \multirow[t]{2}{*}{$\begin{array}{l}\text { Chamber } \\
\text { (gas-particle partitioning) }\end{array}$} & & & 10 & \\
\hline & & & & 100 & \\
\hline & \multirow[t]{2}{*}{$\begin{array}{l}\text { Chamber } \\
\text { (gas-particle- } \\
\text { wall partitioning) }\end{array}$} & & & 10 & \\
\hline & & & & 100 & \\
\hline \multirow[t]{13}{*}{$m$-Xylene } & \multirow[t]{2}{*}{ Ambient } & \multirow[t]{2}{*}{30} & Constant sunlight $^{\mathrm{a}}$ & \multirow[t]{2}{*}{10} & \multirow[t]{2}{*}{ Min: $0.1 ; \max : 120(1 \mathrm{~d}), 300(2-10 \mathrm{~d})$} \\
\hline & & & Diurnal sunlight ${ }^{\mathrm{c}}$ & & \\
\hline & \multirow[t]{5}{*}{ Oxidation flow reactor } & 70 & High lamp setting ${ }^{\mathrm{c}}$ & 10 & \multirow[t]{5}{*}{0.0025} \\
\hline & & 70 & Low lamp setting ${ }^{\mathrm{e}}$ & 10 & \\
\hline & & 30 & Medium lamp setting ${ }^{f}$ & 10 & \\
\hline & & 3 & High lamp setting ${ }^{c}$ & 10 & \\
\hline & & 70 & High lamp setting ${ }^{c}$ & 1000 & \\
\hline & \multirow[t]{2}{*}{ Chamber (gas-phase only) } & \multirow[t]{6}{*}{30} & \multirow[t]{6}{*}{ CU chamber spectrum ${ }^{\mathrm{g}}$} & 10 & \multirow[t]{6}{*}{ Min: 0.1 ; $\max : 120(6 \mathrm{~d}), 300(7-30 \mathrm{~d}$ if needed $)$} \\
\hline & & & & 100 & \\
\hline & $\begin{array}{l}\text { Chamber } \\
\text { (gas-particle partitioning) }\end{array}$ & & & 10 & \\
\hline & & & & 100 & \\
\hline & $\begin{array}{l}\text { Chamber } \\
\text { (gas-particle- } \\
\text { wall partitioning) }\end{array}$ & & & 10 & \\
\hline & & & & 100 & \\
\hline Isoprene & Ambient & 30 & Constant sunlight $^{\mathrm{a}}$ & 10 & Min: $0.1 ; \max : 10(1 \mathrm{~d}), 120(2-10 \mathrm{~d})$ \\
\hline & & & Diurnal sunlight ${ }^{\mathrm{c}}$ & & \\
\hline & Oxidation flow reactor & 70 & High lamp setting ${ }^{c}$ & 10 & 0.001 \\
\hline & & 70 & Low lamp setting $\mathrm{e}$ & 10 & \\
\hline & & 30 & Medium lamp setting ${ }^{f}$ & 10 & \\
\hline & & 3 & High lamp setting ${ }^{\mathrm{c}}$ & 10 & \\
\hline & & 70 & High lamp setting ${ }^{c}$ & 1000 & \\
\hline & & 30 & $\begin{array}{l}\text { Medium lamp setting }{ }^{\mathrm{f}}+5 \times \mathrm{CU} \\
\text { chamber spectrum }^{\mathrm{g}}\end{array}$ & 10 & \\
\hline & & 30 & $\begin{array}{l}\text { Medium lamp setting }{ }^{\mathrm{f}}+10000 \times \\
\text { CU chamber spectrum }\end{array}$ & 10 & \\
\hline
\end{tabular}


Table 1. Continued.

\begin{tabular}{|c|c|c|c|c|c|}
\hline Precursor & Environment & $\begin{array}{l}\text { Relative } \\
\text { humidity }(\%)\end{array}$ & UV & $\begin{array}{l}\text { Initial } \mathrm{OH} \\
\text { reactivity }\left(\mathrm{s}^{-1}\right)\end{array}$ & Integration time step (s) \\
\hline & \multirow[t]{2}{*}{ Chamber (gas-phase only) } & \multirow[t]{6}{*}{30} & \multirow[t]{6}{*}{ CU chamber spectrum ${ }^{\mathrm{g}}$} & 10 & \multirow[t]{6}{*}{ Min: $0.1 ; \max : 10(6 \mathrm{~d}), 120(7-30 \mathrm{~d}$ if needed $)$} \\
\hline & & & & 100 & \\
\hline & \multirow[t]{2}{*}{$\begin{array}{l}\text { Chamber } \\
\text { (gas-particle partitioning) }\end{array}$} & & & 10 & \\
\hline & & & & 100 & \\
\hline & \multirow[t]{2}{*}{$\begin{array}{l}\text { Chamber (gas-particle- } \\
\text { wall partitioning) }\end{array}$} & & & 10 & \\
\hline & & & & 100 & \\
\hline Butane & Ambient & 30 & Constant sunlight $^{\mathrm{a}}$ & 10 & Min: $0.1 ; \max : 120(1 \mathrm{~d}), 300(2-10 \mathrm{~d})$ \\
\hline Heptane & Ambient & 30 & Constant sunlight $^{\mathrm{a}}$ & 10 & Min: $0.1 ; \max : 120(1 \mathrm{~d}), 300(2-10 \mathrm{~d})$ \\
\hline
\end{tabular}

lations but to model zero-NO cases instead. The model cases are listed in Table 1: (i) two cases under ambient conditions, one with constant sunlight at solar zenith angle of $45^{\circ}$ and the other with diurnally varying solar radiation and a noontime solar zenith angle of $0^{\circ}$; (ii) six cases under typical chamber conditions, i.e., low $\left(10 \mathrm{~s}^{-1}\right)$ /high $\left(100 \mathrm{~s}^{-1}\right)$ precursor OHR without gas-particle-wall partitioning, with gas-particle partitioning (no wall) and with gas-particle-wall partitioning; and (iii) five cases under OFR conditions, of which two conditions resulting in significant non-tropospheric organic photolysis (Peng et al., 2016) and one leading to remarkable deviations of $\mathrm{RO}_{2}$ fate from that in the troposphere are not recommended in practice but are still included for completeness since they are similar to conditions in some literature studies (Table 1). For the UV source in chamber cases, we adopt the spectrum of the blacklight and fluorescence light array in the University of Colorado Environmental Chamber Facility (CU chamber; Krechmer et al., 2017). The CU chamber has a volume of $\sim 20 \mathrm{~m}^{3}$, a surface area of $\sim 65 \mathrm{~m}^{2}$, and an estimated wall condensation timescale of $\sim 1000 \mathrm{~s}$ (Krechmer et al., 2016). The parameterization for the reversible gaswall partitioning is taken from Krechmer et al. (2016) with updates of Liu et al. (2019). Wall partitioning in chambers at equilibrium is a function of the surface-to-volume ratio (Krechmer et al., 2016). The timescale to approach equilibrium is expected to be larger in larger chambers but still far shorter than the long experiments needed to investigate high photochemical ages. Therefore differences in wall partitioning timescale are not important for this study. Figure S9 of Krechmer et al. (2016) compared the CU chamber and a few other well-known chambers (including very large ones such as EUPHORE, Siese et al., 2001, and SAPHIR, Rohrer et al., 2005), showing relatively small differences (within a factor of $\sim 2$ in terms of surface-to-volume ratio). Therefore the conclusions about wall partitioning in this study should be approximately applicable to most chambers. The cases under ambient conditions and chamber conditions with low/high precursor OHR are simulated for 10 and 6/30 d, respectively, to encompass an equivalent photochemical age of $>10 \mathrm{~d}$ in each case (given a typical average ambient $\mathrm{OH}$ concentration of $1.5 \times 10^{6}$ molecules $\mathrm{cm}^{-3}$ in the real atmosphere, Mao et al., 2009; see Fig. 1 for the correspondence between equivalent photochemical age and $\mathrm{OH}$ exposure; $\mathrm{OH}_{\text {exp }}$, i.e., the integral of $\mathrm{OH}$ concentration over time). The simulated OFR in the present work employs the light source parametrization obtained by Li et al. (2015) and Peng et al. (2015). UV at both 185 and $254 \mathrm{~nm}$ is used to generate $\mathrm{OH}$, i.e., the OFR185 mode of operation. The residence time in the OFR is always 3 min. Wall losses in the OFR should be smaller than in the chamber, due to reduced wall contact (Brune 2019), and are not simulated here. As several key parameters of the chamber and OFR cases were obtained experimentally at room temperature and atmospheric pressure in Boulder, Colorado, USA (typically $295 \mathrm{~K}$ and $835 \mathrm{mbar}$ ), for an easier comparison, we use these values for the temperature and atmospheric pressure of all model cases.

In addition, we simulate illustrative cases of methane oxidation, under ambient and OFR conditions (Table 1 and Sect. 3.1). Note that these two simulations are performed using the GECKO-A-generated mechanism (see Sect. 2.2) in KinSim (Peng and Jimenez, 2019), a chemical-kinetics solver that is not GECKO-A's default, to avoid possible numerical issues in the GECKO-A internal solver, as methane oxidation by $\mathrm{OH}$ is very slow (Atkinson and Arey, 2003) and very long runs are needed. To characterize trends of OHR evolution (see Sect. 3.5), the ambient cases with constant sunlight are simulated for two more alkanes, i.e., butane and heptane (Table 1). To explore the effects of UV sources in OFR (see Sect. 3.4), two simulations under a typical OFR condition with an additional broad-spectrum UV source (5 and 10000 times the chamber UV source in this study, respectively) are performed for isoprene (Table 1). 


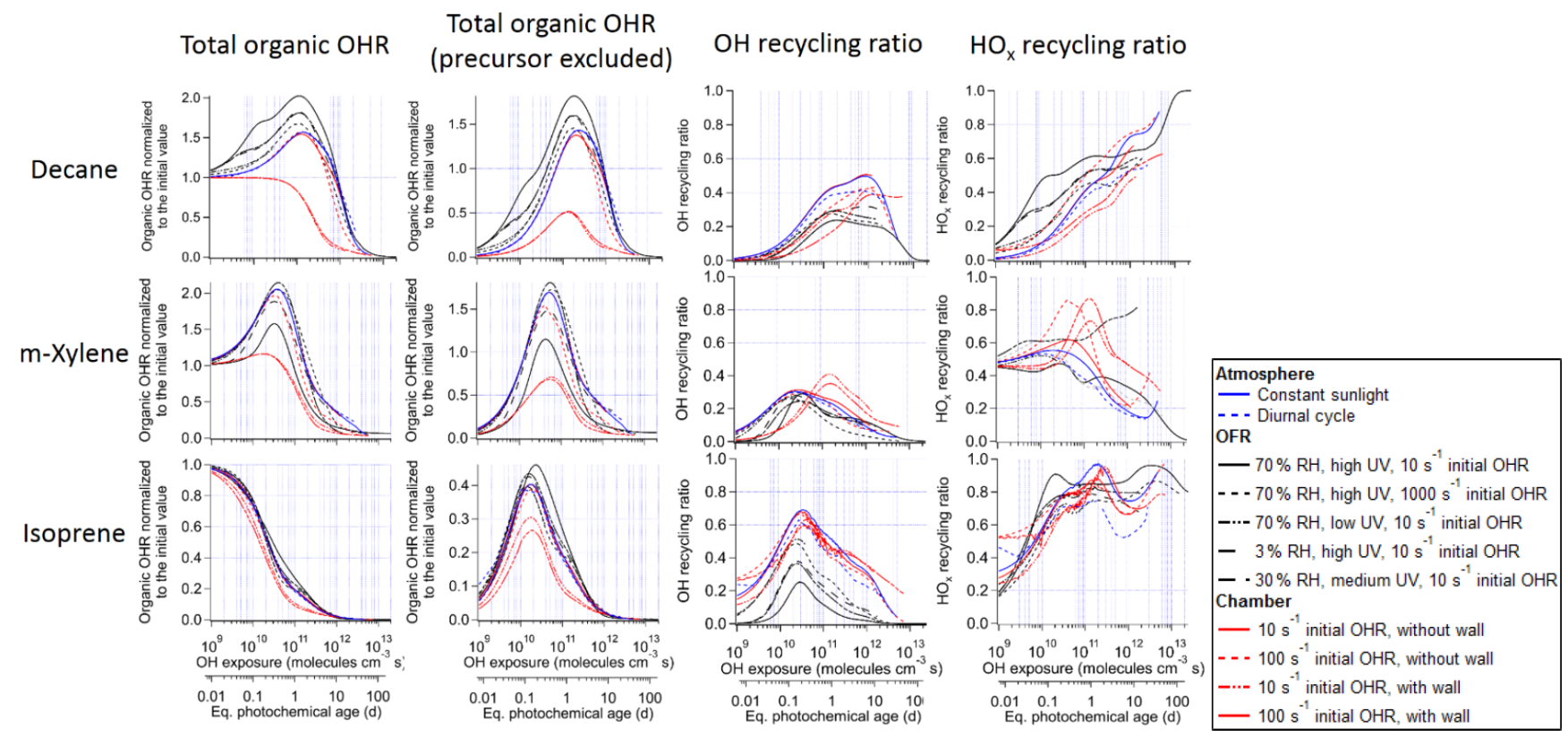

Figure 1. Total organic $\mathrm{OH}$ reactivity $(\mathrm{OHR})$ with and without the contribution of the precursor, $\mathrm{OH}$ recycling ratio $\left(\beta_{1}\right)$, and $\mathrm{HO}_{x}$ recycling ratio $\left(\beta_{2}\right)$ as a function of $\mathrm{OH}$ exposure (or equivalent photochemical age; second $x$ axis) in the photooxidations of decane, isoprene, and $m$-xylene under different conditions in the atmosphere, oxidation flow reactor (OFR), and chamber.

\subsection{The GECKO-A model}

GECKO-A (Aumont et al., 2005; with updates as described by Camredon et al., 2007; Valorso et al., 2011; Lee-Taylor et al., 2015) is an explicit chemical model which uses known mechanisms and rates supplemented with experimentally based structure-activity relationships (SARs) to generate comprehensive atmospheric oxidation mechanisms for organic species. The mechanisms are implemented within a box model with a two-step solver (Verwer, 1994; Verwer et al., 1996). In mechanism generation, isomer lumping for mechanism reduction purposes is applied to certain products with branching ratios $<1 \%$ (here typically $\mathrm{N}$-containing products, which are not relevant for our simulations). It has a negligible impact on the results.

The core isoprene scheme in GECKO-A is adopted from the Master Chemical Mechanism (MCM) v3.3.1 (Jenkin et al., 2015), while the meta-xylene oxidation mechanism follows MCM v3.2 (Jenkin et al., 2003, Bloss et al., 2005), typically until ring-breaking occurs, whereupon the GECKO-A mechanism generator implements the standard SAR protocols as described by Aumont et al. (2005), Camredon et al. (2007), and Lee-Taylor et al. (2015). Under the zero-NO conditions employed in this study, we find that, in two of the four $m$-xylene reaction channels (xylenol, $17 \%$; and MXYLO2, 4\%), some product species persist anomalously owing to a lack of alternative reaction pathways in the MCM. We therefore allow GECKO-A to apply the standard SARs to two cyclic non-aromatic products of xylenol (MXYOLO2 and MXYOLOOH in the $51 \%$ xylenol OH-oxidation channel; see Scheme S1 in the Supplement). We also introduce $\mathrm{OH}$ oxidation of MXYCATECH and MXY1OOH (in the $42 \%$ and $7 \%$ xylenol $\mathrm{OH}$-oxidation channels) and of MXYLOOH and MXYLAL (in the MXYLO2 channel), assuming similarity to the MCM OH oxidation of xylenol to MXYOLO2, and with net $\mathrm{OH}$ rate constants estimated using the EPA EPI Suite software package (US EPA, 2012). MXYLOOH, MXCATECH, and MXYLAL each yield between two and six bicyclic non-aromatic substituted peroxy radicals, with net $\mathrm{OH}$ rate constants of $1.77 \times 10^{-11}$, $1.56 \times 10^{-10}$, and $8.6 \times 10^{-13} \mathrm{~cm}^{3} \mathrm{molec}^{-1} \mathrm{~s}^{-1}$, respectively. (The MXYLOOH $\mathrm{OH}$ rate also includes MXYLAL production). MXY1OOH is assigned a substituted single-ring hydroxy-ketone product, with $\mathrm{OH}$ rate constant $3.26 \times 10^{-11} \mathrm{~cm}^{3} \mathrm{molec}^{-1} \mathrm{~s}^{-1}$. The early part of the metaxylene reaction scheme used in this work is shown in Scheme S1.

We tested the effect of solver integration time step length on output precision. The output species concentrations in all simulations but for isoprene OFR (Table 1) converge well as integration time step decreases (Fig. S1 in the Supplement). In the isoprene OFR test cases, the output values oscillate over a small range $(\lesssim 5 \%)$ for integration time steps $<0.01 \mathrm{~s}$ (Fig. S1). Since this numerical error is smaller than typical rate constant measurement uncertainties (from $\sim 10 \%$ to a factor of 2-3; Burkholder et al., 2015), as well as the uncertainties related to the SARs used in GECKO-A, it is deemed acceptable for the relevant simulations in this study. The integration time step for each simulation in the present work is reported in Table 1. 
We allow mechanism generation to proceed through to $\mathrm{CO}_{2}$ production in most cases in this study. The only exception is for extremely-low-volatility species (saturation vapor pressure $<10^{-13} \mathrm{~atm}$ ) which are considered to be completely and irreversibly partitioned to the particle phase. Particle- and wall-phase species are no longer considered in the OHR budget, since heterogeneous oxidation is much slower than gas-phase oxidation (e.g., George and Abbatt, 2010). Gas-particle-wall partitioning is activated only for the chamber cases where wall effects are considered. For the ambient cases and the chamber cases without gas-wall partitioning, gas-particle partitioning is also disabled to avoid artificial condensation of gases into the particle phase. In environments with very low NO (e.g., remote atmosphere), organic aerosol concentration is typically $0.2 \mu \mathrm{g} \mathrm{m}^{-3}$ (Hodzic et al., 2020), while most major intermediates/products have higher saturation concentrations $\left(C^{*}\right)$ and hence largely stay in the gas phase. $C^{*}$ is calculated using the parameterization of Nannoolal et al. (2008) (default option of GECKOA). Although SIMPOL (Pankow and Asher, 2008) was recommended by Krechmer et al. (2016) to estimate $C^{*}$ for the chamber wall partitioning treatment using their parameterization, the $C^{*}$ estimates by the Nannoolal and SIMPOL parameterizations are close (generally within a factor of 2) for the species that can reversibly partition between the gas and wall phases $\left(C^{*} \sim 0.1-1000 \mu \mathrm{g} \mathrm{m}^{-3}\right)$ in this study. This difference is smaller than the uncertainties of the Krechmer et al. (2016) parameterization. Therefore, the use of the parameterization of Nannoolal et al. (2008) for $C^{*}$ estimation is acceptable.

Concerns have previously been expressed about nonconservation of carbon in GECKO-A (Mouchel-Vallon et al., 2020). This has proven in the current simulations to be almost entirely due to lack of accounting for product $\mathrm{CO}_{2}$ in some handwritten reactions. We edited the handwritten isoprene and $m$-xylene schemes (see above and Sect. 2.2.3) for carbon balance, which reduced simulation-end carbon losses in the $m$-xylene and isoprene ambient cases with constant UV from $4 \%$ and $9 \%$, respectively, to negligible levels $(<0.4 \%$; Fig. S2).

For the current study, we have made several updates to GECKO-A, i.e., (i) inclusion of key OFR-specific radical reactions, (ii) extension of the UV range considered to cover 185 and $254 \mathrm{~nm}$, and (iii) updates to the NO-free $m$-xylene oxidation mechanism, so that GECKO-A is able to simulate OFR chemistry and the entire process of NO-free $m$-xylene photooxidation (until $\mathrm{CO} / \mathrm{CO}_{2}$ ). We will describe these three updates below.

\subsubsection{Key radical reactions in oxidation flow reactor}

We have added several reactions that are unimportant in the troposphere but that are required to fully represent the radical chemistry within the OFR ( $\mathrm{Li}$ et al., 2015). The most important inorganic reactions are $\mathrm{H}_{2} \mathrm{O}+h v$
$(185 \mathrm{~nm}) \rightarrow \mathrm{H}+\mathrm{OH}, \mathrm{O}_{2}+h v(185 \mathrm{~nm}) \rightarrow 2 \mathrm{O}\left({ }^{3} \mathrm{P}\right)$, and $\mathrm{O}_{3}+h v(254 \mathrm{~nm}) \rightarrow \mathrm{O}\left({ }^{1} \mathrm{D}\right)+\mathrm{O}_{2}$. These three reactions, together with $\mathrm{O}\left({ }^{3} \mathrm{P}\right)+\mathrm{O}_{2}+\mathrm{M} \rightarrow \mathrm{O}_{3}+\mathrm{M}$ and $\mathrm{O}\left({ }^{1} \mathrm{D}\right)+\mathrm{H}_{2} \mathrm{O}$ $\rightarrow 2 \mathrm{OH}$, which are already in the GECKO-A inorganic radical chemistry scheme, are responsible for the OH generation in OFR. The OFR radical chemistry has previously been modeled in detail using KinSim (Peng and Jimenez, 2019), which was validated against experimental observations ( $\mathrm{Li}$ et al., 2015; Peng et al., 2015). A comparison between KinSim and GECKO-A for a range of OFR conditions shows typical agreement between the two models within $2 \%$ for key outputs.

Due to high $\mathrm{OH}$ in OFR, reaction of $\mathrm{RO}_{2}$ with $\mathrm{OH}$ is also included in mechanism generation, with an assumed rate constant of $1 \times 10^{10} \mathrm{~cm}^{3} \mathrm{molec}^{-1} \mathrm{~s}^{-1}$ (Peng et al., 2019). The products of this type of reaction are assumed to be $\mathrm{RO}$ (alkoxy radical) $+\mathrm{HO}_{2}$ for alkyl $\mathrm{RO}_{2}$ and $\mathrm{R}$ (alkyl radical) $+\mathrm{CO}_{2}+\mathrm{HO}_{2}$ for acyl $\mathrm{RO}_{2}$. Although these reactions for certain $\mathrm{RO}_{2}$ may have reaction intermediates, the reactions of the intermediates (with $\mathrm{OH}$ ) are believed to be very fast under OFR conditions where $\mathrm{OH}$ is much higher than in the atmosphere (Peng and Jimenez, 2020), and hence only the probable final products (no intermediates) of these reactions are included in mechanism generation. The reaction of $\mathrm{RO}_{2}$ with $\mathrm{OH}$ is not included in the mechanisms for the ambient and chamber simulations due to low contribution of this pathway to the $\mathrm{RO}_{2}$ fate in those cases.

\subsubsection{Organic photolysis at 185 and $254 \mathrm{~nm}$}

Organic photolysis is assessed in GECKO-A via a lookup table of $j$ values for reference chromophores pre-calculated at different solar zenith angles with the Tropospheric Ultraviolet and Visible (TUV) 1-D radiative transfer model (Madronich and Flocke, 1999). The reference cross sections used in the model generally do not cover the UV wavelengths at which OFR operates (with narrow peaks at 185 and $254 \mathrm{~nm}$ ) since they are not tropospherically relevant. Thus it was necessary to extend to $185 \mathrm{~nm}$ the relevant reference absorption cross sections. We have done this using literature values via the Mainz UV-Vis spectral atlas (Keller-Rudek et al., 2020) or by extrapolating the available cross-section data, using other similar chromophores as references. Details of all cross-section extensions are given in Table S1 in the Supplement. Where quantum yield information was not available, we assume values of unity since photons at 185 and $254 \mathrm{~nm}$ are usually sufficiently energetic to make photolysis occur (Ausloos and Lias, 1971). In case of multiple product channels for a photolyzed molecule, the branching ratios of those channels at 185 and $254 \mathrm{~nm}$ are estimated through extrapolation of branching ratio data from available ranges followed by a renormalization. Finally, we apply the OFR UV spectrum within TUV to calculate OFR-relevant $j$-value lookup tables. 


\subsubsection{Mechanism of NO-free $\boldsymbol{m}$-xylene oxidation}

The meta-xylene oxidation mechanism in GECKO-A follows MCM v3.2 until all aromatic, epoxy, or bridged-peroxy rings are broken (See Scheme S1). Since the MCM was designed for typical urban environments with abundant $\mathrm{NO}_{x}$, it omits some reaction pathways for other oxidants, assuming them to be of negligible importance. The relevant photolysis loss pathways are slow under ambient conditions and inactive in the OFR case. This leads to persistence and accumulation of certain hydroperoxides and their interconverting peroxy radicals under NO-free conditions. We added two NO-free oxidation reactions to the xylenol branch of the meta-xylene oxidation scheme, Scheme S1. In the $51 \%$ branch, we allow the unsaturated bicyclic peroxide MXYLOOH to react with, sequentially, $\mathrm{OH}$ (estimating $k_{\mathrm{VOC}+\mathrm{OH}} \sim 3 \times 10^{-11} \mathrm{~cm}^{3} \mathrm{molec}^{-1} \mathrm{~s}^{-1}$ ) and $\mathrm{HO}_{2}$ (estimating $k_{\mathrm{RO}_{2}+\mathrm{HO}_{2}} \sim 1 \times 10^{-11} \mathrm{~cm}^{3}$ per molecule per second), to produce a saturated bicyclic peroxide (denoted "TT8001" in Scheme S1). In the $42 \%$ branch, we add a competing $\mathrm{O}_{3}$ reaction with the alkoxy radical MXCATEC1O, producing an unsaturated carbonyl alkoxy radical 1T8000, which eliminates $\mathrm{CH} 3$ to form the unsaturated cyclic hydroxy dicarbonyl TU7000. Both products are then further oxidized via the standard GECKO SARs.

\subsection{GECKO Loader and Plotter}

To allow GECKO-A outputs, which are usually highly complex and voluminous, to be explored and visualized in detail on standard (non-UNIX) personal computers, we have developed the GECKO Loader and Plotter based in the dataanalyzing and graphic-making package Igor Pro 8.0 (WaveMetrics, Lake Oswego, Oregon, USA). This tool assists in the rapid and detailed analysis of model-chamber/OFR comparison studies.

Specifically, the GECKO Loader and Plotter facilitates: (i) filtering the (sometimes extremely large and finely resolved) model results time series to examine specific characteristics, (ii) identifying the most abundant and/or influential species in each phase (gas, particle, and wall), (iii) selecting species by specific chemical identity (molecular formula, specific formula, and/or functional group identity), (iv) plotting time series of individual species and their formation/destruction rates, (v) assessing and displaying aggregated properties (volatility distribution, mass spectrum, Henry's law constant distribution) of the product mixture and subsets thereof, and (vi) calculating bulk characteristics of the simulation $\left(\mathrm{OH}_{\text {exp }}, \mathrm{OHR}_{\mathrm{VOC}}\right.$, light intensity, elemental ratios, etc.) and relating species abundances to them.

\section{Results and discussions}

In this section, we will show the evolution of $\mathrm{OHR}_{\mathrm{VOC}}$ in the photooxidation of different precursors under various condi- tions. To aid the presentation of this evolution for larger precursors, whose oxidation is more complex, the oxidation of the simplest VOC, i.e., methane, will be first discussed. After presenting the results of individual precursors, we will compare the results between conditions and between precursors to illustrate the general trends. Along with the OHR evolution, the $\mathrm{OH}$ recycling ratio $\left(\beta_{1}\right.$, defined as number of $\mathrm{OH}$ molecules generated from organic reactions per $\mathrm{OH}$ consumed by organics) and $\mathrm{HO}_{x}\left(=\mathrm{OH}+\mathrm{HO}_{2}\right)$ recycling ratio ( $\beta_{2}$, defined as number of $\mathrm{OH}$ and $\mathrm{HO}_{2}$ molecules generated from organic reactions per $\mathrm{OH}$ consumed by organics) will also be discussed, as they are important parameters that may considerably affect the budget of atmospheric oxidizing agents (Stone et al., 2012) and the $\mathrm{HO}_{2}$-to- $\mathrm{OH}$ ratio and $\mathrm{RO}_{2}$ chemistry in OFR (Peng et al., 2015, 2019).

\subsection{Methane}

To explain one of the main features in the OHR evolution in VOC photooxidation, i.e., $\mathrm{OHR}_{\mathrm{VOC}}$ peaking at a certain $\mathrm{OH}_{\text {exp }}$, the oxidation of $\mathrm{CH}_{4}$ is employed as an example because of its simpler mechanism (Scheme S2). The results of this oxidation under the ambient condition show that $\mathrm{OHR}_{\mathrm{VOC}}$ peaks at an $\mathrm{OH}_{\exp }$ of about $1 \times 10^{13}$ molecules $\mathrm{cm}^{-3} \mathrm{~s}$ (Fig. S3). As the OHR of the precursor always decreases during its oxidation, the appearance of such a peak of $\mathrm{OHR}_{\mathrm{VOC}}$ before all VOCs are finally oxidized to $\mathrm{CO}_{2}$ indicates that the OHR increase from intermediates and products is faster than the OHR decrease of the precursor. This is obviously the case for $\mathrm{CH}_{4}$ oxidation, as there is no significant $\mathrm{CH}_{4}$ loss before $\mathrm{OH}_{\text {exp }}$ $\sim 10^{13}$ molecules $\mathrm{cm}^{-3} \mathrm{~s}$ by its very slow reaction with $\mathrm{OH}$ (rate constant on the order of $10^{-15} \mathrm{~cm}^{3} \mathrm{molec}^{-1} \mathrm{~s}^{-1}$; Atkinson and Arey, 2003) and all the non- $\mathrm{CO}_{2}$ intermediates/products of the oxidation $\left(\mathrm{CH}_{3} \mathrm{OOH}, \mathrm{CH}_{3} \mathrm{OH}, \mathrm{HCHO}\right.$, and $\mathrm{CO}$ ) are orders of magnitude more reactive toward $\mathrm{OH}$ than is $\mathrm{CH}_{4}$ (Atkinson and Arey, 2003). This large difference in precursor and intermediate/product oxidation timescales allows the oxidations of intermediates/products (including $\mathrm{CO}$, whose reaction rate constant with $\mathrm{OH}$ is $\sim 2 \times 10^{-13} \mathrm{~cm}^{3} \mathrm{molec}^{-1} \mathrm{~s}^{-1}$; Burkholder et al., 2015) to establish a steady state, whereby the OHR of the intermediates/products is proportional to the concentration/OHR of $\mathrm{CH}_{4}$. After $\mathrm{OH}_{\text {exp }} \sim 10^{13}$ molecules $\mathrm{cm}^{-3} \mathrm{~s}, \mathrm{CH}_{4}$ concentration decay and consequently that of all intermediates/products become significant, giving the OHR VOC peak around $1 \times 10^{13}$ molecules $\mathrm{cm}^{-3} \mathrm{~s}$.

We also performed a simulation under a typical OFR condition. The OHR ${ }_{\text {VOC }}$ peak also appears around $1 \times 10^{13}$ molecules $\mathrm{cm}^{-3} \mathrm{~s}$ in this case for the same reasons discussed above, but its height is almost twice that of the ambient case (Fig. S3). The OHR of CO in both cases is similar, while that of $\mathrm{CH}_{3} \mathrm{OH}$ is higher in the ambient case but those of $\mathrm{CH}_{3} \mathrm{OOH}$ and $\mathrm{HCHO}$ are significantly higher in the OFR case. This is because the relative importance of the various 
reactions involved in $\mathrm{CH}_{4}$ oxidation (Scheme S2) depends on the conditions in each reactor.

In the OFR case, $\mathrm{OH}$ and $\mathrm{HO}_{2}$ concentrations are $\sim 4$ and $\sim 3$ orders of magnitude higher than typical ambient values, respectively (Peng et al., 2015). The reactions of two intermediates, $\mathrm{CH}_{3} \mathrm{OOH}$ and $\mathrm{HCHO}$, with $\mathrm{OH}$ and the reaction of the only major $\mathrm{RO}_{2}$ involved, $\mathrm{CH}_{3} \mathrm{OO}$, with $\mathrm{HO}_{2}$ are much faster than their photolysis or the selfreaction of $\mathrm{CH}_{3} \mathrm{OO}$ (Scheme S2). Neglecting organic photolysis and $\mathrm{CH}_{3} \mathrm{OO}$ self-reaction (and thus $\mathrm{CH}_{3} \mathrm{OH}$ as a product of the latter), the mechanism of $\mathrm{CH}_{4}$ oxidation can be simplified to an $\mathrm{OH}$-driven chain $\left(\mathrm{CH}_{4} \rightarrow \mathrm{CH}_{3} \mathrm{OOH}\right.$ $\rightarrow \mathrm{HCHO} \rightarrow \mathrm{CO} \rightarrow \mathrm{CO}_{2}$ ) with a fast steady-state branch on $\mathrm{CH}_{3} \mathrm{OOH}\left(\mathrm{CH}_{3} \mathrm{OOH} \leftrightarrow \mathrm{CH}_{3} \mathrm{OO}\right)$. For a simple chain, as we show in Appendix A that the OHR of precursor and that of each intermediate are equal. At the OHR VOC peak, the OHR of $\mathrm{HCHO}$ and $\mathrm{CO}$ are very close to that of $\mathrm{CH}_{4}$, while that of $\mathrm{CH}_{3} \mathrm{OOH}$ is larger, because the branch reaction $\mathrm{CH}_{3} \mathrm{OOH}+\mathrm{OH} \rightarrow \mathrm{CH}_{3} \mathrm{OO}+\mathrm{H}_{2} \mathrm{O}$ also contributes to OHR but does not affect the chain (and hence the OHR of the downstream species). With such an idealized chain mechanism, the OHR $\mathrm{VOC}_{\mathrm{C}}$ peak height equals the precursor OHR multiplied by the number of steps needed to produce $\mathrm{CO}_{2}$.

In contrast, the OHR $\mathrm{VOC}_{\mathrm{C}}$ peak height (and its composition) in the ambient case cannot be explained by the simple chain. Both $\mathrm{HCHO}$ photolysis and $\mathrm{CH}_{3} \mathrm{OO}$ self-reaction play a major role in the oxidation in this case and are significantly faster than the reactions in the simple chain $(\mathrm{HCHO}+\mathrm{OH}$ and $\mathrm{CH}_{3} \mathrm{OO}+\mathrm{HO}_{2}$ ). In terms of the relationship of these two reactions with the chain, $\mathrm{HCHO}$ photolysis bypasses $\mathrm{HCHO}+\mathrm{OH}$ in converting $\mathrm{HCHO}$ to $\mathrm{CO}$, while $\mathrm{CH}_{3} \mathrm{OO}$ self-reaction bypasses $\mathrm{CH}_{3} \mathrm{OOH}$, in effect short-circuiting the involvement of $\mathrm{OH}$ in the oxidation and hence lowering

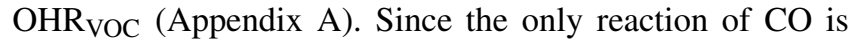
$\mathrm{CO}+\mathrm{OH}$, its OHR at the OHR VOC peak is essentially unaltered.

\subsection{Decane}

\subsubsection{Ambient and OFR cases}

The evolution of OHR ${ }_{\mathrm{VOC}}$ during the oxidation of another alkane, decane, and under ambient and OFR conditions exhibits a smaller difference and smaller peak enhancements than those in the methane cases (Fig. 1), although the chain lengths of the decane oxidation to $\mathrm{CO}_{2}$ should be much longer than that of methane. The ambient cases with constant and diurnal solar radiation have almost the same OHR VOC evolution as a function of $\mathrm{OH}_{\exp }$ (Figs. 1 and 2).

These differences from the methane cases arise because a key assumption of the simple reaction chain model, i.e., slow precursor decay allowing intermediates/products to build up and reach a steady state, no longer holds in decane oxidation. The main first-generation products, i.e., secondary decyl hydroperoxides, react with $\mathrm{OH}$ only less-than-3-times more

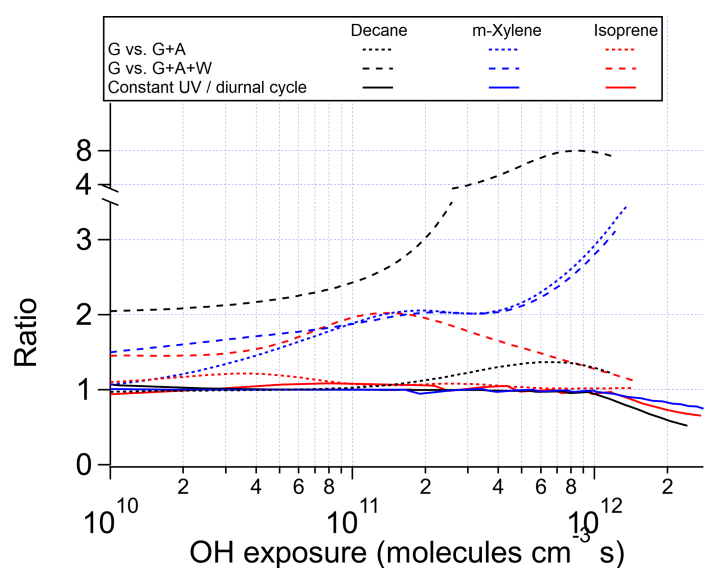

Figure 2. Ratios of OHR of the products present in the gas phase between the chamber cases without gas-particle-wall partitioning and (i) with gas-particle (G vs. G + A) or (ii) gas-particle-wall partitioning (G vs. $\mathrm{G}+\mathrm{A}+\mathrm{W}$ ) at initial OHR of $10 \mathrm{~s}^{-1}$, as well as between the ambient cases with constant and diurnal sunlight for the photooxidations of decane, $m$-xylene, and isoprene as a function of $\mathrm{OH}$ exposure.

rapidly (in terms of the rate constant of the whole molecule) than does decane, as the significant activation effect of the -OOH group only applies to the $\alpha-\mathrm{H}$, and all other $\mathrm{H}$ atoms in this long chain alkyl, though less reactive, can be abstracted by OH (Kwok and Atkinson, 1995; Aumont et al., 2005). When decyl hydroperoxides are present in significant amounts $\left(\mathrm{OH}_{\exp } \sim 5 \times 10^{10}\right.$ molecules $\mathrm{cm}^{-3}$ s), decane loss is also significant (Fig. 3). Also, oxidation of monohydroperoxides to ketones, their most likely fate (due to the activated $\alpha-\mathrm{H})$, lowers $\mathrm{OHR}_{\mathrm{VOC}}$, as the oxidation removes the most activated H (Kwok and Atkinson, 1995). The multifunctional products of further oxidation in the middle $\mathrm{OH}_{\exp }$ range (before $\sim 2 \times 10^{11}$ molecules $\mathrm{cm}^{-3}$ s) mainly have $\mathrm{OOH}$ and -CO- (Fig. 4), which do not further increase OHR substantially with respect to monohydroperoxides, for similar reasons as the comparison of monohydroperoxides with decane. After the OHR ${ }_{V O C}$ peak, the precursor is largely consumed and $-\mathrm{CH}(\mathrm{OOH})$ - groups become increasingly oxidized to - $\mathrm{CO}-$ in both monohydroperoxides and multifunctional hydroperoxides (Figs. 3 and 4), which rapidly decreases OHR VOC. Since the decane oxidation chain does not reach a steady state, it results in only limited $\mathrm{OHR}_{\mathrm{VOC}}$ enhancement at peak.

In the absence of steady state for the nodes (stable species) in the decane oxidation chains (nodes far downstream insufficiently populated), organic photolysis and $\mathrm{RO}_{2}$ self- and cross-reactions only help move OHR contributors to downstream nodes but do not significantly change their total concentrations. This is shown by the relatively small differences in the composition of stable OHR contributors between the ambient and OFR cases (Fig. 3). The remarkable difference between these cases is the contribution of $\mathrm{RO}_{2}$ to OHR, 

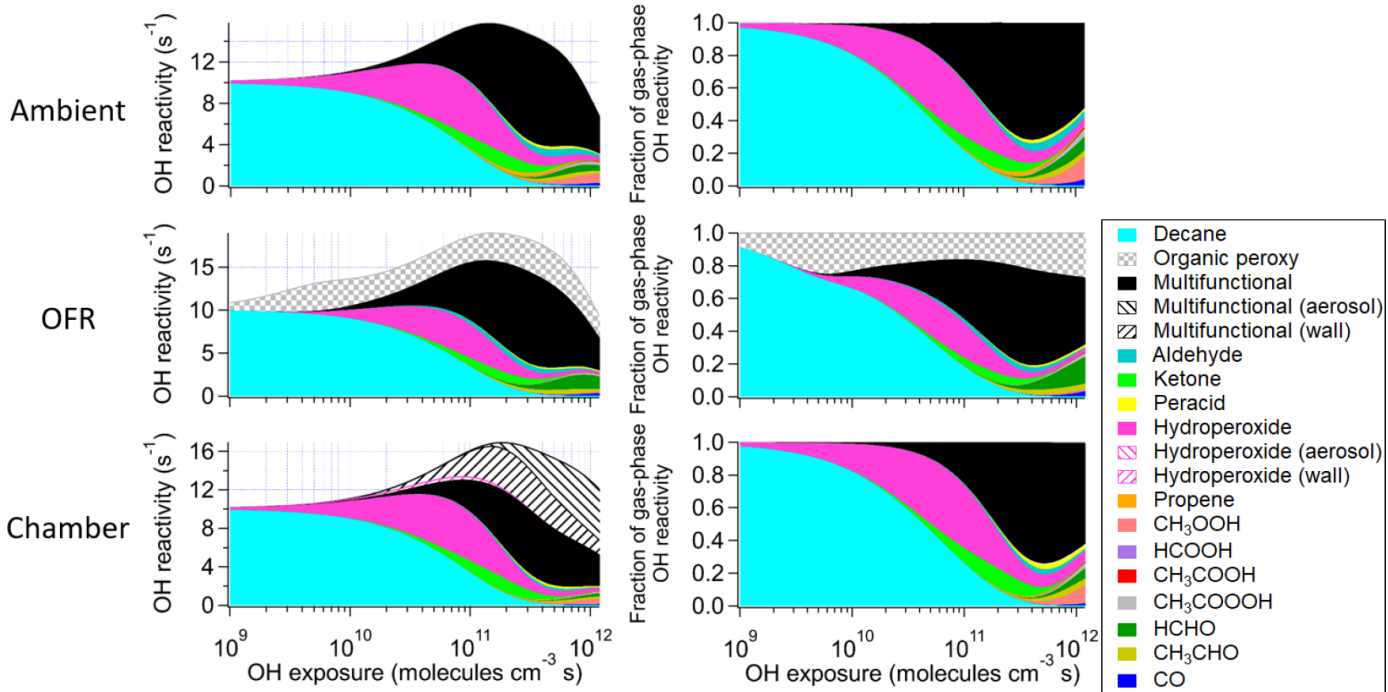

Figure 3. Absolute and fractional contributions to the organic OHR during decane photooxidation of the main species and types of species as a function of $\mathrm{OH}$ exposure in the ambient case with constant sunlight; the OFR case with relative humidity of $30 \%$, medium UV lamp setting, and initial OHR of $10 \mathrm{~s}^{-1}$; and the chamber case with initial OHR of $10 \mathrm{~s}^{-1}$ and gas-wall partitioning. The types of species shown in this figure exclude the $\mathrm{C} 1$ and $\mathrm{C} 2$ species listed separately. The OHR of the particle- and wall-phase species are the values as if those species were gas-phase OHR contributors, although they actually do not react with $\mathrm{OH}$ in the simulations.

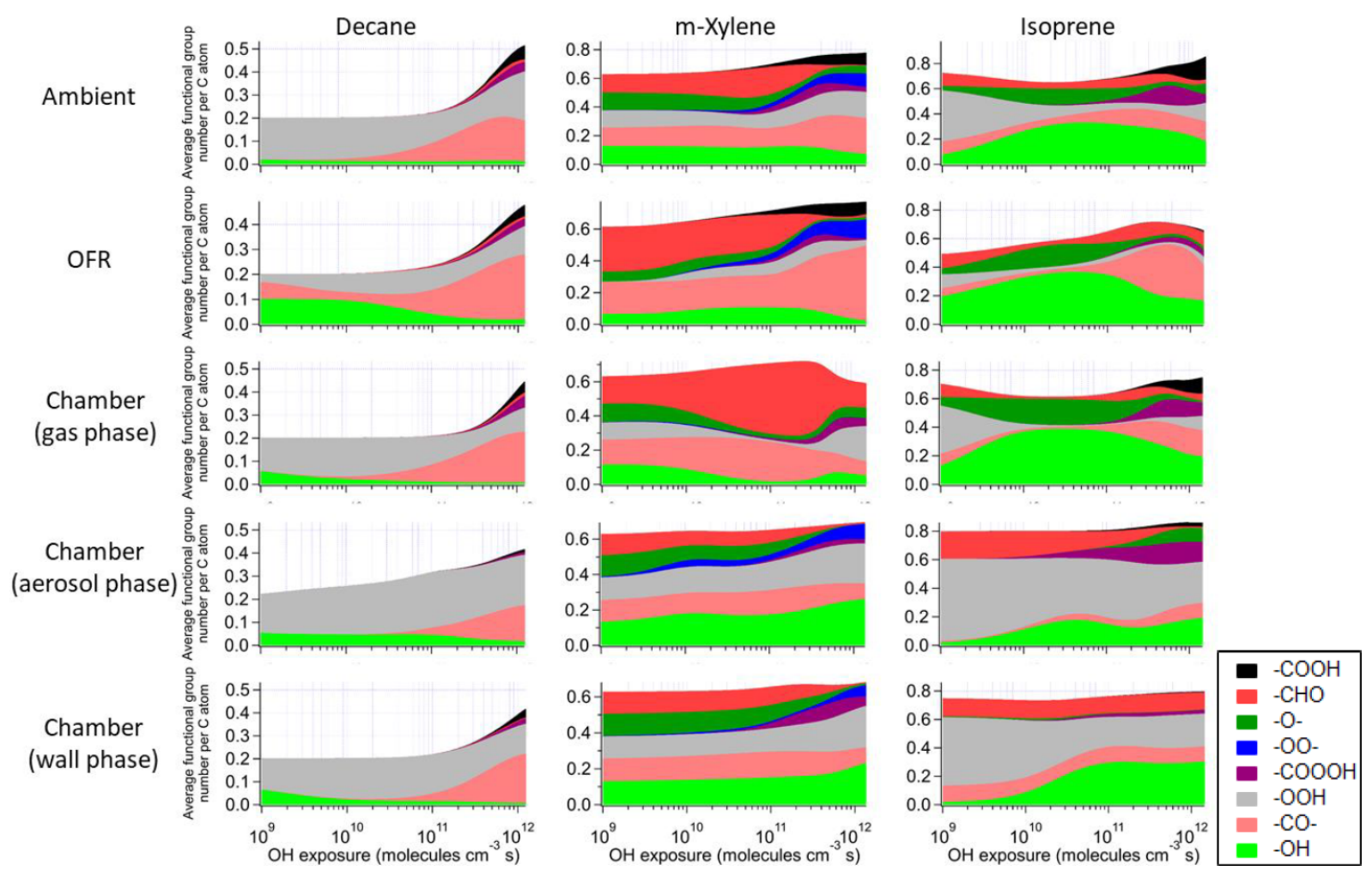

Figure 4. Average number of functional group per $\mathrm{C}$ atom as a function of $\mathrm{OH}$ exposure in the saturated multifunctional species in the ambient case with constant sunlight, the OFR case with relative humidity of $70 \%$, high UV lamp setting, and initial OHR of $10 \mathrm{~s}^{-1}$, as well as the gas, aerosol, and wall phases in the chamber case with initial OHR of $10 \mathrm{~s}-1$ and gas-particle-wall partitioning of the photooxidations of decane, $m$-xylene, and isoprene. Note that the functional group "-O-" represents ether, ester, and epoxy groups in the GECKO-A model. 
which is as high as $\sim 3 \mathrm{~s}^{-1}$ in the OFR case shown in Fig. 3, while estimated to be only up to $\sim 0.1 \mathrm{~s}^{-1}$ in the ambient case, given the $\mathrm{RO}_{2}$ concentration in the simulation.

It is known that $\mathrm{RO}_{2}+\mathrm{OH}$ can be a significant $\mathrm{RO}_{2}$ loss pathway in OFR, especially when $\mathrm{OH}$ and $\mathrm{HO}_{2}$ production is relatively strong (higher relative humidity (RH) and UV). We have previously advised to avoid such conditions in lowNO chemistry based on simplified modeling, because of its high-NO-like organic product (Peng et al., 2019). Here our chemically explicit modeling results show that the limitation for OFR chemistry caused by $\mathrm{RO}_{2}+\mathrm{OH}$ may not be as serious as suggested by Peng et al. (2019), at least in terms of OHR $\mathrm{VOC}$ and, to some extent, of organic composition (Fig. 3). The condition of the OFR case shown in Fig. 3 (30\% $\mathrm{RH}$, medium UV, and $10 \mathrm{~s}^{-1}$ initial OHR) is a compromise between the goals of reaching an equivalent photochemical age of $\sim 10 \mathrm{~d}$, avoiding significant non-tropospheric organic photolysis, and keeping a more atmospherically relevant $\mathrm{RO}_{2}$ chemistry (Peng et al., 2016; Peng et al., 2019; Peng and Jimenez, 2020). In this case, the fractional contribution of $\mathrm{RO}_{2}+\mathrm{OH}$ to $\mathrm{RO}_{2}$ fate is still sizable ( $>30 \%$ ). However, the evolution of the composition of monofunctional species in this OFR case before the OHR VOC peak equivalent age is similar to that in the ambient case (Fig. 3), as hydroperoxide production through $\mathrm{RO}_{2}+\mathrm{HO}_{2}$ is still the main loss pathway of the first-generation $\mathrm{RO}_{2}$ and $\mathrm{RO}$ produced from $\mathrm{RO}_{2}+\mathrm{OH}$ can also form ketones, i.e., the main secondgeneration products. The other main fate of RO, i.e., isomerization, leads to slightly faster production of multifunctional species, since the product of the recombination of the immediate product of this isomerization, i.e., an alkyl radical, with $\mathrm{O}_{2}$ is already a bifunctional $\mathrm{RO}_{2}$. This isomerization also creates a hydroxyl group on the $\mathrm{C}$ backbone, resulting in a relatively high share of hydroxyl in the functional groups of the multifunctional species (Fig. 4).

Before the OHR VOC peak, as $\mathrm{OH}_{\text {exp }}$ increases, carbonyls accumulate. They are prone to Norrish-type photochemistry (Turro et al., 2009), which plays a major role in the OHR evolution after the OHR VOC $_{\text {peak }}$ in the ambient cases by breaking $\mathrm{C} 10$ species into smaller molecules (Fig. 3). Alkenes, which can only be produced via Norrish type II reaction in this case (Turro et al., 2009), are non-negligible OHR contributors around $3 \times 10^{11}$ molecules $\mathrm{cm}^{-3} \mathrm{~s}$. A set of oxygenated $\mathrm{C} 1$ and $\mathrm{C} 2$ species are also largely produced through organic photolysis followed by reactions with $\left(\mathrm{O}_{2}\right.$ and $) \mathrm{HO}_{2}$. Organic photolysis, along with $\mathrm{OH}$ reaction pathways can also produce $\mathrm{RO}_{2}$. Self- and crossreactions of acylperoxy radicals, which are formed in significant amounts in this $\mathrm{OH}_{\text {exp }}$ range, can rapidly generate alkoxy radicals (Orlando and Tyndall, 2012), which may decompose subsequently (Ziemann and Atkinson, 2012). At $\sim 1 \times 10^{12}$ molecules $\mathrm{cm}^{-3} \mathrm{~s}$, the small species produced account for about half of OHR $\mathrm{VOC}_{\mathrm{C}}$ in the ambient cases (Fig. 3). In the OFR cases, organic photolysis is usually much weaker than in the atmosphere (Peng et al., 2016; Peng and Jimenez,
2020), as the negligible OHR of alkenes in the OFR case in Fig. 3 also indicates. However, fragmentation of multifunctional species does not appear to be significantly weaker in the OFR case than in the ambient case shown in Fig. 3. This is largely due to fast $\mathrm{RO}_{2}+\mathrm{OH}$. The reactions of acylperoxys with $\mathrm{OH}$ lead to direct fragmentation (Orlando and Tyndall, 2012). Highly functionalized RO can also form from the reactions of multifunctional $\mathrm{RO}_{2}$ with $\mathrm{OH}$ and then often rapidly decompose. $\mathrm{RO}_{2}+\mathrm{OH}$ also results in a major difference of the OFR case from the ambient case at high equivalent ages (Fig. 3), i.e., lower (higher) OHR contribution from $\mathrm{CH}_{3} \mathrm{OOH}$ (HCHO) in OFR than in the atmosphere. Most $\mathrm{CH}_{3} \mathrm{OO}$ reacts with $\mathrm{OH}$ to produce $\mathrm{CH}_{3} \mathrm{O}$ and then $\mathrm{HCHO}$ in the OFR case, leaving a minor fraction of $\mathrm{CH}_{3} \mathrm{OO}$ reacting with $\mathrm{HO}_{2}$ to form $\mathrm{CH}_{3} \mathrm{OOH}$.

\subsubsection{Chamber cases}

Three types of chamber simulations, without gas-particlewall partitioning, with gas-particle partitioning only (no wall), and with gas-particle-wall partitioning, are considered in this study. The first type has almost the same results as the ambient cases in terms of the evolution of OHR $\mathrm{VOC}$ and its composition as a function of $\mathrm{OH}_{\text {exp }}$ (Fig. 1). Despite different spectra, sunlight and chamber lights cover the same wavelength range and usually generate oxidizing agent radicals (e.g., $\mathrm{OH}$ and $\mathrm{HO}_{2}$ ) in similar amounts. Therefore, all key parameters are very similar between the ambient case with constant solar radiation and the chamber case (with $10 \mathrm{~s}^{-1}$ initial OHR) and without gas-particle-wall partitioning. This explains the high similarities between the results of the ambient cases and the chamber cases without wall partitioning. Unfortunately, the lack of wall partitioning is not realistic for current chambers.

The chamber cases with gas-particle-wall partitioning at lower initial OHR, which are realistic, show very large deviations from the ambient cases that cannot be explained by gas-particle partitioning only (Figs. 1, 3 and S4). These deviations are mostly due to wall partitioning of OVOCs around the $\mathrm{OH}_{\exp }$ of the $\mathrm{OHR}$ peak and at lower $\mathrm{OH}_{\text {exp. In this }}$ $\mathrm{OH}_{\text {exp }}$ range, the wall removes about half of the OHR of decane oxidation intermediates/products (Figs. 1 and 2) and hence also almost removes the OHR VOC peak in the relevant chamber cases (Fig. 1). In detail, some decyl hydroperoxides partition to the wall in the chamber case shown in Fig. 3, as decyl is a relatively large alkyl and leads to hydroperoxides of sufficiently low volatility to promote wall partitioning. The C10 ketones, usually of higher volatility than the corresponding hydroperoxides, do not show significant wall partitioning (Fig. 3), while about half of the multifunctional C10 species, of even lower volatility than the corresponding hydroperoxides, are partitioned to the wall.

At higher $\mathrm{OH}_{\exp }\left(>2 \times 10^{11}\right.$ molecules $\left.\mathrm{cm}^{-3} \mathrm{~s}\right)$, more multifunctional species stay in the gas phase or partition to the particle phase (Figs. 3 and S4). Those in the gas phase are 
formed via $\mathrm{C} 10$ fragmentation and are thus of higher volatility (Fig. 3). Those partitioned to the particle phase instead of the wall are due to a higher organic aerosol concentration resulting from accumulation during a long oxidation. The substantial partitioning of multifunctional species to aerosol and the wall also slows down their oxidative evolution in the gas phase relative to the ambient cases (Fig. 4). The degree of oxidation of products partitioned to the particle phase increases since low $\mathrm{OH}_{\text {exp }}$. This is due to a volatility fractionation caused by the lower ability of the particle phase to absorb condensable organic gases than that of the wall phase at this $\mathrm{OH}_{\text {exp. At low organic aerosol loading, the relative potential }}$ of particle partitioning to wall partitioning for organic gases of higher functionalization is higher than for those of lower functionalization.

At higher initial OHR $\left(100 \mathrm{~s}^{-1}\right)$, and hence higher organic aerosol loading, condensable gases have a significantly higher tendency of partitioning to the particle phase. The reduction of OHR of the higher initial OHR chamber case with aerosol partitioning only (no wall partitioning) relative to the purely gas-phase case is comparable to the lower initial OHR case with gas-particle-wall partitioning at low $\mathrm{OH}_{\exp }$ (before the OHR peak) (Fig. S4). At high $\mathrm{OH}_{\text {exp }}$, this OHR reduction is even stronger than in the lower initial OHR case with gas-particle-wall partitioning, as partitioning of OVOCs to the particle phase dominates over that to the walls.

As $\mathrm{OH}_{\text {exp }}$ increases and large multifunctional species are formed in increasing amounts from oxidation, their substantial partitioning to aerosol and the wall decreases the OHR of decane oxidation intermediates/products by a factor up to 8 around $1 \times 10^{12}$ molecules $\mathrm{cm}^{-3} \mathrm{~s}$ compared to the chamber cases without gas-particle-wall partitioning (Figs. 2 and S4). At higher $\mathrm{OH}_{\text {exp }}$ (long oxidation times) gas-phase concentrations of partitioning species decline, allowing reverse partitioning back from the particle phase and the wall which then serves as a source rather than a sink. As a result, the ratio of the OHR of oxidation intermediates/products in the chamber case with gas-particle-wall partitioning to that without this partitioning decreases (Fig. 2).

\subsection{3 $\mathrm{OH}$ and $\mathrm{HO}_{x}$ recycling ratios}

As discussed above, we also compute $\mathrm{OH}\left(\beta_{1}\right)$ and $\mathrm{HO}_{x}$ $\left(\beta_{2}\right)$ recycling ratios in decane oxidation. Note that these quantities also include $\mathrm{OH}$ and $\mathrm{HO}_{2}$ generated as a result of organic photolysis. The differences in these recycling ratios between the simulated cases are relatively small. $\beta_{1}$ is close to 0 at $\mathrm{OH}_{\exp } \lesssim 1 \times 10^{10}$ molecules $\mathrm{cm}^{-3}$ s (Fig. 1 ), as the initial reaction of decane with $\mathrm{OH}$ only produces an $\mathrm{RO}_{2}$ and subsequently $\mathrm{C} 10$ hydroperoxides and no $\mathrm{HO}_{x}$. Then $\beta_{1}$ undergoes a fast increase between $\sim 1 \times 10^{10}$ and $1 \times 10^{11}$ molecules $\mathrm{cm}^{-3} \mathrm{~s}$ (Fig. 1), as the further oxidation of $\mathrm{C} 10$ hydroperoxides to ketones fully recycles $\mathrm{OH}\left(\mathrm{R}_{1}\right.$ $\left.\mathrm{CH}(\mathrm{OOH})-\mathrm{R}_{2}+\mathrm{OH} \rightarrow \mathrm{R}_{1}-\mathrm{CO}-\mathrm{R}_{2}+\mathrm{H}_{2} \mathrm{O}+\mathrm{OH}\right)$ in the ambient and chamber cases. Nevertheless, $\beta_{1}$ only increases up to $\sim 0.4$ at this stage in the ambient and chamber cases, as oxidation of $\mathrm{C} 10$ hydroperoxides to dihydroperoxy species and precursor oxidation also account for a substantial fraction of $\mathrm{OH}$ loss but do not recycle it. In the OFR cases, $\beta_{1}$ only increases up to $\sim 0.2-0.3$ at this stage, since $\mathrm{RO}_{2}+\mathrm{OH}$ starts to be active but does not recycle $\mathrm{OH}$. Then, $\beta_{1}$ roughly plateaus up to $\sim 1 \times 10^{12}$ molecules $\mathrm{cm}^{-3} \mathrm{~s}$, as the overall effect of the decrease in hydroperoxy concentration, reducing $\mathrm{OH}$ recycling, and the increase in the concentration of acylperoxy, enhancing $\mathrm{OH}$ recycling through its reaction with $\mathrm{HO}_{2}$ (Orlando and Tyndall, 2012), is relatively small. Finally, $\beta_{1}$ gradually decreases to 0 (Fig. 1), as all OVOCs degrade to highly oxidized $\mathrm{C} 1$ species, i.e., $\mathrm{HCHO}, \mathrm{HCOOH}$, and $\mathrm{CO}$, which only have $\mathrm{HO}_{2}$ recycling but no $\mathrm{OH}$ recycling, and the unreactive $\mathrm{CO}_{2}$.

The $\mathrm{HO}_{x}$ recycling ratio $\left(\beta_{2}\right)$ in decane oxidation is similar to $\beta_{1}$ before $\sim 1 \times 10^{11}$ molecules $\mathrm{cm}^{-3} \mathrm{~s}$ for the ambient and chamber cases, as only $\mathrm{OH}$ (but not $\mathrm{HO}_{2}$ ) is recycled at this stage. $\beta_{2}$ is a little higher in the OFR cases than in the other cases at this stage because of the $\mathrm{HO}_{2}$ recycling by $\mathrm{RO}_{2}+\mathrm{OH}$. However, at higher $\mathrm{OH}_{\text {exp }}$, $\beta_{2}$ continues to increase with $\mathrm{OH}_{\exp }$ to a final value of 1 (Fig. 1). This difference between $\beta_{1}$ and $\beta_{2}$ is by definition due to $\mathrm{HO}_{2}$ recycling. Its significance rises in parallel with that of organic photolysis, which can often produce $\mathrm{HCO}$ radicals and acylperoxy radicals. The former extremely rapidly undergoes $\mathrm{HCO}+\mathrm{O}_{2} \rightarrow \mathrm{CO}+\mathrm{HO}_{2}$; the latter can rapidly convert peroxy radicals to alkoxy radicals (Orlando and Tyndall, 2012), which may then react with $\mathrm{O}_{2}$ to generate $\mathrm{HO}_{2}$ (Ziemann and Atkinson, 2012). At very high $\mathrm{OH}_{\exp }\left(10^{12}-10^{13}\right.$ molecules $\left.\mathrm{cm}^{-3} \mathrm{~s}\right)$, reactive highly oxidized small VOCs are the dominant OHR contributors, and many of them recycle $\mathrm{HO}_{2}$ during their oxidation by $\mathrm{OH}$ (Fig. 3). Finally, once $\mathrm{CO}$ becomes the only remaining OHR contributor, $\beta_{2}$ is 1 .

\section{$3.3 \quad m$-Xylene}

Most features in $m$-xylene oxidation can be explained based on similar discussions as for decane oxidation in Sect. 3.2. $\mathrm{OHR}_{\mathrm{VOC}}$ also has a maximum during the oxidation (Figs. 1 and S4), as most of the direct products of $m$-xylene oxidation by $\mathrm{OH}$, i.e., the unsaturated carbonyl (MXYEPOXMUC in MCM v 3.2 notation; see Scheme S1), the unsaturated endocyclic peroxide (MXYBPEROOH), and xylenols, are more reactive toward $\mathrm{OH}$ than $m$-xylene. The OHR of these initial products is enhanced much more during the oxidation of $m$ xylene than of decane, owing to the creation of $\mathrm{C}=\mathrm{C}$ bonds in many post-aromatic (ring-opening) products; hence the OHR $_{\text {VOC }}$ peak enhancement in $m$-xylene oxidation is larger than in decane oxidation. Because the reaction rate constant of $m$-xylene with $\mathrm{OH}$ slightly exceeds that of decane, the $\mathrm{OHR}_{\text {VOC }}$ peak in $m$-xylene oxidation occurs at slightly lower $\mathrm{OH}_{\text {exp }}$ than in decane oxidation (Fig. 1). In the OFR case under the same condition as the decane case shown in Fig. 3, 
the evolution of OHR of the stable organic species is again similar to that in the ambient case. And OHR vOC is higher in the OFR case again mainly due to OHR from $\mathrm{RO}_{2}$ (Figs. 1 and S4). Several main first- and second-generation products are already highly functionalized through fast $\mathrm{O}_{2}$ addition (Scheme S1), and they are also often unsaturated and prone to further functionalization. Therefore, the degree of functionalization in saturated aliphatic multifunctional species is much higher in $m$-xylene than in decane oxidation (Fig. 4). Also, as several aromatic-scheme-specific reaction types occur in the early stages of $m$-xylene oxidation, e.g., endo- $\mathrm{O}_{2}$ addition (creating - $\mathrm{OO}-$ ) and ring-opening (creating - $\mathrm{CO}-$ , $-\mathrm{CHO}$, etc.), multifunctional species functionality is more diverse than in decane oxidation (Fig. 4). Photolysis again plays a role in species fragmentation and the production of highly oxidized $\mathrm{C} 1$ and $\mathrm{C} 2$ species after the $\mathrm{OHR}_{\mathrm{VOC}}$ peak (Fig. S4).

At low $\mathrm{OH}_{\text {exp }}$ and that of the $\mathrm{OHR}_{\mathrm{VOC}}$ peak, particle and wall partitioning also substantially reduces the OHR $\mathrm{VOC}_{\mathrm{C}}$ in the relevant chamber cases of $m$-xylene oxidation while the OHR $_{\text {VOC }}$ reduction due to partitioning to the particle phase is smaller than that due to the wall (Figs. 1, 2, S4 and S5). The precursor ( $m$-xylene) is a C8 species, and even many firstgeneration products of its oxidation are highly oxygenated (Scheme S1) lower-volatility species. The relative reduction of OHR of the intermediates/products also increases with $\mathrm{OH}_{\text {exp }}$ before the $\mathrm{OH}_{\text {exp }}$ of the OHR peak, as volatile species are oxidized and become more prone to wall partitioning (Figs. 2 and S4). At higher $\mathrm{OH}_{\text {exp }}$, more condensed organics are partitioned to the particle phase because of high organic aerosol concentration (Fig. S4), and the wall and aerosol again serve as OVOC source (Fig. 2).

The evolution of $\beta_{1}$ and $\beta_{2}$ in $m$-xylene oxidation is somewhat different than in decane oxidation (Fig. 1). In the ambient cases, they are non-negligible even at $\mathrm{OH}_{\exp }$ as low as $1 \times 10^{9}$ molecules $\mathrm{cm}^{-3} \mathrm{~s}(\sim 0.05$ and $\sim 0.45$, respectively $)$. $\mathrm{OH}$ is mainly recycled from one of the endo-cyclic peroxide routes $\left(m\right.$-xylene $+\mathrm{OH}+2 \mathrm{O}_{2} \rightarrow$ MXYBIPERO2; MXY$\mathrm{BIPERO} 2+\mathrm{HO}_{2} \rightarrow \mathrm{MXYBPEROOH}+\mathrm{O}_{2}$; MXYBPER$\mathrm{OOH}+\mathrm{OH} \rightarrow \mathrm{MXYOBPEROH}+\mathrm{H}_{2} \mathrm{O}+\mathrm{OH}$, Scheme $\mathrm{S} 1$ ), which involve various functional groups and open the possibility of radical recycling. The third step of this route is very fast (with a rate constant on the order of $10^{-10} \mathrm{~cm}^{3} \mathrm{molec}^{-1} \mathrm{~s}^{-1}$ ). Once the second step takes place, the third step contributes to $\mathrm{OH}$ recycling. However, in the OFR cases with strong water vapor photolysis (not in the other OFR cases), the third step does not play a significant role, and $\beta_{1}$ is $\sim 0$ at very low $\mathrm{OH}_{\text {exp }}$ (Fig. 1) due to the relatively slow second step $\left(\mathrm{RO}_{2}+\mathrm{HO}_{2}\right)$. In the former cases, this is due to the relatively slow second step $\left(\mathrm{RO}_{2}+\mathrm{HO}_{2}\right)$, while in the latter cases, the highly oxygenated compounds partition to the wall even more rapidly (in hundreds of seconds; Krechmer et al., 2016) than their reactions with $\mathrm{HO}_{x}$. Strong $\mathrm{HO}_{2}$ recycling occurs in all simulated cases from the beginning of the oxidation (Fig. 1), since two of the three ma- jor channels of $m$-xylene $+\mathrm{OH}$ (i.e., those forming MXYEPOXMUC and xylenol, respectively) produce $\mathrm{HO}_{2}$ as well.

As more multifunctional species are formed (particularly through ring-opening) near the $\mathrm{OH}_{\text {exp }}$ of the peak OHR $\mathrm{VOC}$, $\mathrm{HO}_{x}$ recycling is also active, with $\beta_{1}$ increasing and $\beta_{2}$ remaining high (Fig. 1). There is a high peak in $\beta_{2}$ for the chamber case with high initial OHR $\left(100 \mathrm{~s}^{-1}\right)$ and no aerosol or wall partitioning. It results from $\mathrm{RO}_{2}$ cross-reactions, many of which produce alkoxy radicals that subsequently yield carbonyls and $\mathrm{HO}_{2}$ through reactions with $\mathrm{O}_{2}$ (Orlando and Tyndall, 2012). $\mathrm{RO}_{2}$ cross-reactions are significant in that $\mathrm{OH}_{\exp }$ range also because (i) high precursor concentration translates into higher $\mathrm{RO}_{2}$ concentration and (ii) acylperoxy radicals, whose reactions with other $\mathrm{RO}_{2}$ are fast (Orlando and Tyndall, 2012), are rapidly formed from the oxidation of -CHO groups in the ring-opening products (Scheme S1). The chamber case with high initial OHR and gas-particle-wall partitioning does not have such a high $\beta_{2}$ peak, because of fast partitioning of the oxidation products containing - $\mathrm{CHO}$ groups to the aerosol and wall phases, which significantly reduces acylperoxy radical concentration around the $\mathrm{OH}_{\text {exp }}$ of the peak OHR $\mathrm{VOC}$. At higher $\mathrm{OH}_{\text {exp }}$, the calculated $\beta_{1}$ and $\beta_{2}$ become less reliable, since remaining apparent OHR contributors may in fact be persistent artifacts of the incompleteness of the (handwritten) $m$-xylene oxidation mechanism which may substantially bias $\beta_{1}$ and $\beta_{2}$ when the concentrations of remaining OHR contributors should be generally low. Therefore, we do not try to interpret the features in $\beta_{1}$ and $\beta_{2}$ at high $\mathrm{OH}_{\exp }$ for $m$-xylene oxidation.

\subsection{Isoprene}

The most salient difference of the $\mathrm{OHR}_{\mathrm{VOC}}$ evolution in the photooxidation of isoprene from that of the other precursors in this study is the lack of OHR VOC peak in the isoprene cases (Figs. 1 and S5). The decrease in OHR $\mathrm{VOC}_{\text {all along }}$ this photooxidation is expected since the reaction of isoprene with $\mathrm{OH}$ is very fast (at $1 \times 10^{-10} \mathrm{~cm}^{3} \mathrm{molec}^{-1} \mathrm{~s}^{-1}$; Atkinson and Arey, 2003), and all intermediates/products of this photooxidation react with $\mathrm{OH}$ more slowly than isoprene. The $\mathrm{OHR}_{\mathrm{VOC}}$ of the intermediates/products peaks slightly after an $\mathrm{OH}_{\text {exp }}$ of $1 \times 10^{10}$ molecules cm ${ }^{-3} \mathrm{~s}$ (Fig. 1). At this $\mathrm{OH}_{\text {exp }}$, the main type of the first-generation products, oxygenated unsaturated species (e.g., isoprene-derived unsaturated hydroxyl hydroperoxides, ISOPOOH), are largely produced from isoprene $+\mathrm{OH}$ and their loss rates (with rate constant with $\mathrm{OH}$ slightly lower than that of isoprene) reach the maxima (Fig. S5). Further oxidation leads to the loss of all $\mathrm{C}=\mathrm{C}$ bonds in the isoprene $\mathrm{C}$ backbone and thus a substantial drop of the OHR of the molecule.

Before $\mathrm{OH}_{\mathrm{exp}} \sim 5 \times 10^{10}$ molecules $\mathrm{cm}^{-3} \mathrm{~s}$ in isoprene photooxidation, the main deviations from the ambient cases shown by the chamber cases with wall partitioning are again caused by wall partitioning of multifunctional species, but 
their relative magnitudes are different than in the photooxidations of decane and $m$-xylene, with the impacts of wall partitioning being smaller (Fig. S5). Oxygenated species derived from isoprene, a C5 species, should be generally more volatile and less prone to wall partitioning than those derived from decane and $m$-xylene. On the other hand, isoprene reacts with $\mathrm{OH}$ much more rapidly than do decane or $m$-xylene, creating a larger deviation from the steady state for $\mathrm{RO}_{2}$ directly derived from isoprene and a more remarkable decrease in the OHR of the first-generation products (Fig. S5). In the OFR case shown in Fig. S5, $\mathrm{RO}_{2}$ contributes negligibly to $\mathrm{OHR}_{\mathrm{VOC}}$, since many first-generation isoprene-derived $\mathrm{RO}_{2}$ have other very fast loss pathways and the very fast decay of isoprene cannot sustain $\mathrm{RO}_{2}$ production at $\mathrm{OH}_{\exp } \gtrsim 1 \times 10^{10}$ molecules $\mathrm{cm}^{-3} \mathrm{~s}$.

After $\mathrm{OH}_{\mathrm{exp}} \sim 5 \times 10^{10}$ molecules $\mathrm{cm}^{-3} \mathrm{~s}$, the deviation caused by chamber wall partitioning becomes more significant as highly oxidized and lower-volatility multifunctional species (Fig. 4) are formed in significant amounts (Figs. 2 and S6). However, aerosol partitioning does not become more significant as, in the chamber cases of isoprene oxidation, aerosol formation is always so small that partitioning to the particle phase never competes with that to the walls. At very high $\mathrm{OH}_{\text {exp }}$, the wall again acts as a source of OVOCs in isoprene oxidation, as in those of the other precursors (Fig. 2). The deviations of OFR cases from the ambient cases are mainly caused by $\mathrm{RO}_{2}+\mathrm{OH}$ and lack of organic photolysis. These two effects lead to too much HCHO produced and inefficient production of other $\mathrm{C} 1$ and $\mathrm{C} 2$ species (Fig. S5).

To test whether one of the issues, i.e., lack of organic photolysis in OFR, can be mitigated by adding tropospherically relevant UV sources, we perform two additional simulations. Adding the emissions corresponding to the high Hg lamp setting with 5 times the UV of the CU chamber (a rough upper limit for experimental implementation) has a negligible effect (Fig. S6). To reach a ratio between tropospherically relevant UV (UVA+UVB) intensity and $\mathrm{OH}$ concentration similar to that in the ambient case with constant sunlight requires addition of a chamber light $\sim 10000$ times stronger than the CU chamber light. Such a strong UV source is obviously not realistic, and, while it does increase both early organic photolysis and the relative contribution of $\mathrm{C} 1$ and $\mathrm{C} 2$ photoproducts to OHRVOC around $2 \times 10^{11}$ molecules $\mathrm{cm}^{-3} \mathrm{~s}$ (Fig. S6), it increases the deviation of this OFR case from the ambient cases at very high $\mathrm{OH}_{\text {exp }}$, where oxidation of $\mathrm{C} 1$ and $\mathrm{C} 2$ species to $\mathrm{CO}$ proceeds much more rapidly than in the atmosphere.

Product functionality in isoprene oxidation is more diverse than in decane oxidation (Fig. 4). This is due to both the active isomerization and the propensity of the isoprene $\mathrm{C}=\mathrm{C}$ bonds prone to addition of various groups (Wennberg et al., 2018). Notably, epoxy groups in species such as isoprenederived epoxydiol (IEPOX) account for a large fraction of saturated product functionality (Fig. 4), particularly at $\mathrm{OH}_{\text {exp }}$ on the order of $10^{10}$ molecules $\mathrm{cm}^{-3} \mathrm{~s}$. In the gas phase of the chamber cases with wall partitioning, the overwhelming majority of saturated multifunctional organic molecules are IEPOX up to $1 \times 10^{11}$ molecules $\mathrm{cm}^{-3} \mathrm{~s}$ (Fig. 4), as more highly oxidized species mostly partition to the wall.

IEPOX formation from isoprene-derived hydroperoxide (ISOPOOH) oxidation by $\mathrm{OH}$ (ISOPOOH $+\mathrm{OH}$ $\rightarrow$ IEPOX $+\mathrm{OH}$ ) leads to the peak of $\mathrm{OH}$ recycling around $3 \times 10^{10}$ molecules $\mathrm{cm}^{-3} \mathrm{~s}$ (Fig. 1). OH recycling is active even at very low $\mathrm{OH}_{\exp }\left(1 \times 10^{9}\right.$ molecules $\left.\mathrm{cm}^{-3} \mathrm{~s}\right)$ because a significant amount of ISOPOOH forms early and can recycle $\mathrm{OH}$ through its oxidation, except in the OFR cases with strong water vapor photolysis, where ISOPOOH cannot be efficiently formed from first-generation $\mathrm{RO}_{2} \cdot \mathrm{HO}_{2}$ recycling is also active in the entire course of the photooxidation (Fig. 1), because of a number of isomerization and photolysis pathways that form alkoxy radicals and highly oxidized $\mathrm{C} 1$ species such as $\mathrm{HCOOH}, \mathrm{HCHO}$, and $\mathrm{CO}$ at very high $\mathrm{OH}_{\text {exp }}$ (Fig. S5).

\subsection{Trends in OHR per $\mathrm{C}$ atom}

To explore some general trends of OHR evolution in VOC photooxidation, simulations are performed for the ambient cases with constant UV for two additional alkanes between methane and decane, i.e., butane and heptane. The results of these simulations are compared to the existing analogous cases in Fig. 5. For all cases, the $\mathrm{OHR}_{\mathrm{VOC}}$ peak height decreases and the $\mathrm{OH}_{\exp }$ of the OHRVOC peak shifts towards lower $\mathrm{OH}_{\text {exp }}$, as the $\mathrm{C}$ number of the precursor alkane increases. This can be explained by the fact that the $\mathrm{OH}$ rate constants of these alkanes increase with $\mathrm{C}$ number and suggests a possible general trend between OHR peak location and $\mathrm{C}$ number.

To explore these trends further, we calculate the OHR per unit starting concentration of $\mathrm{C}$ atom (in the precursor) in all ambient cases with constant UV in this study (Fig. 5b). In this study, $\mathrm{CO}_{2}$ is not included initially but produced during the oxidation. Therefore, $\mathrm{C}$ atoms in the produced $\mathrm{CO}_{2}$ are taken into account in the calculation of OHR per $\mathrm{C}$ atom. For real atmospheric cases, initial $\mathrm{CO}_{2}$ is present but should not be considered in this calculation. Note that OHR per $\mathrm{C}$ atom has a unit of $\mathrm{cm}^{3}$ per atom per second and represents the average contribution to the rate constant with $\mathrm{OH}$ of all considered $\mathrm{C}$ atoms. Despite large differences among the reactivities of these precursors, the OHR per $\mathrm{C}$ atom in the simulations of all precursors but methane converges near an $\mathrm{OH}_{\text {exp }}$ of $3 \times 10^{11}$ molecules $\mathrm{cm}^{-3} \mathrm{~s}$ and then follows a very similar downward trend (Fig. 5b). This $\mathrm{OH}_{\text {exp }}$ value is roughly where saturated multifunctional species have their maximal relative contribution to the OHRVOC (Figs. 3 and S5). Even in the ambient cases of $m$-xylene oxidation, saturated multifunctional species also account for about half of OHR VOC when the contribution of aromatics, some of which may artificially persist due to mechanism incompleteness, is excluded 


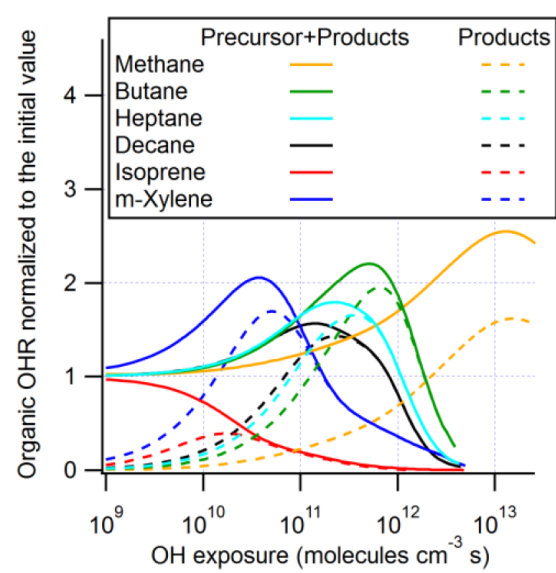

(a)

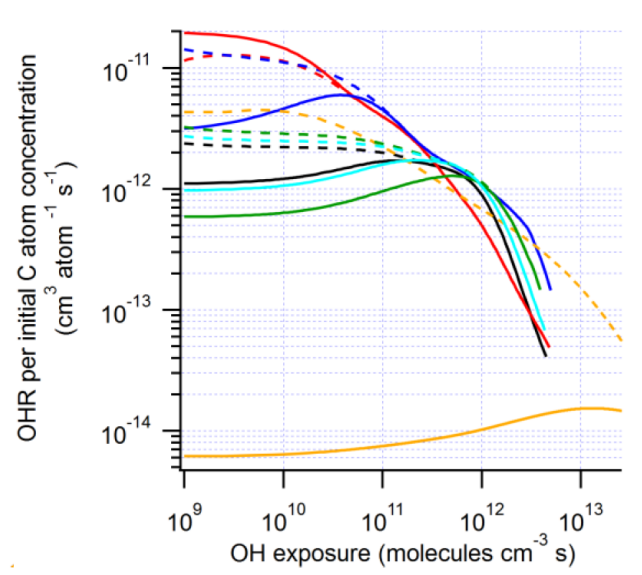

(b)

Figure 5. (a) OHR and (b) OHR per initial C atom concentration of the organics (including and excluding the precursor) as a function of $\mathrm{OH}$ exposure in the ambient cases with constant sunlight of the photooxidation of methane, butane, heptane, decane, isoprene, and $m$-xylene.

(Fig. S4). Also, at $\mathrm{OH}_{\mathrm{exp}}>\sim 3 \times 10^{11}$ molecules $\mathrm{cm}^{-3} \mathrm{~s}$, a $\mathrm{C}$ atom in saturated multifunctional species on average has at least 0.3 functional groups in the ambient cases (Fig. 4), and the functional group composition is relatively diverse at this $\mathrm{OH}_{\text {exp }}$. Therefore, the convergence value of OHR per $\mathrm{C}$ atom of $\sim 2 \times 10^{-12} \mathrm{~cm}^{3}$ per atom per second at $\sim 3 \times 10^{11}$ molecules $\mathrm{cm}^{-3} \mathrm{~s}$ can be largely regarded as a relatively invariant average of those of secondary $\mathrm{H}$ and $\alpha-\mathrm{H}$ of various O-containing functional groups. Note that this average is for NO-free conditions and can be lower at high NO due to deactivating effects of $\mathrm{N}$-containing groups formed during oxidation (Isaacman-VanWertz and Aumont, 2021).

Before the convergence, isoprene has the highest OHR per $\mathrm{C}$ atom (on the order of $10^{-11} \mathrm{~cm}^{3}$ per atom per second) among the precursors and intermediates/products (Fig. 5b), because of its conjugated $\mathrm{C}=\mathrm{C}$ bonds. The OHR per $\mathrm{C}$ atom of its first-generation oxidation products is slightly lower and close to that of the oxidation intermediates/products of $m$ xylene, as the main contributors in both cases are oxygenated monoalkenes. The average OHR per $\mathrm{C}$ atom of the studied alkanes increases with $\mathrm{C}$ number (Fig. 5b), with the upper limit around $1 \times 10^{-12} \mathrm{~cm}^{3}$ per atom per second consistent with Kwok and Atkinson (1995), since the less-reactive $-\mathrm{CH}_{3}$ groups (with OHR per $\mathrm{C}$ atom of $\sim 1 \times 10^{-13} \mathrm{~cm}^{3}$ per atom per second) contribute proportionally less to molecular OHR as $\mathrm{C}$ number increases. Conversely, the early-stage products of alkane oxidation (mainly alkyl monohydroperoxides) show higher average OHR per $\mathrm{C}$ atom for shorter molecules (Fig. 5b), owing to the activating (increasing OHR) contribution of the $-\mathrm{OOH}$ group.

Following the convergence of $\mathrm{OHR}$ per $\mathrm{C}$ atom, this quantity in all non-methane ambient cases in this study sees a similar decay (Fig. 5b). This coincides with multifunctional species broken into small highly oxidized $\mathrm{C} 1$ and $\mathrm{C} 2$ compounds. Although among them there are species with
OHR per $\mathrm{C}$ atom $>5 \times 10^{-12} \mathrm{~cm}^{3}$ per atom per second (e.g., $\mathrm{CH}_{3} \mathrm{OOH}, \mathrm{CH}_{3} \mathrm{CHO}$, and $\mathrm{HCHO}$ ), the average OHR per $\mathrm{C}$ atom of these $\mathrm{C} 1$ and $\mathrm{C} 2$ species is mainly governed by those reacting more slowly (e.g., $\mathrm{HCOOH}$ and particularly $\mathrm{CO}$ ) and hence reaching higher concentrations amid the fast decay of multifunctional species. The similar fast drop of OHR per $\mathrm{C}$ atom after $\mathrm{OH}_{\text {exp }} \sim 1 \times 10^{12}$ molecules $\mathrm{cm}^{-3} \mathrm{~s}$ for various precursors implies a transition from OHR from saturated multifunctional molecules to OHR from $\mathrm{CO}$ before the final oxidation to $\mathrm{CO}_{2}$ (which has zero OHR).

\subsection{Total $\mathrm{OH}$ consumption for each precursor}

Integrating $\mathrm{OHR}$ per $\mathrm{C}$ atom over $\mathrm{OH}_{\exp }$ allows us to assess the average number of $\mathrm{OH}$ molecules consumed by each $\mathrm{C}$ atom during the entire course of oxidation. This quantity can also be apportioned to the contributions of different $\mathrm{OH}$ reactants (Fig. 6). Due to incomplete oxidation of several species, especially $\mathrm{CO}$, the value of this quantity for an oxidation with all $\mathrm{C}$ atoms ending up with $\mathrm{CO}_{2}$ should be higher than those at simulation end $\left(\mathrm{OH}_{\mathrm{exp}} \sim 4 \times 10^{12}\right.$ molecules $\left.\mathrm{cm}^{-3} \mathrm{~s}\right)$. We correct this in Fig. 6 by including additional contribution of $\mathrm{CO}$ to make its total contribution 1 , since $\mathrm{CO}$, the typical penultimate product, consumes one $\mathrm{OH}$ molecule in its final oxidation but is still present in significant quantities at the end of our simulations. Thus, each $\mathrm{C}$ atom reacts with $\mathrm{OH}$ around three times in the course of the oxidation of isoprene and decane to $\mathrm{CO}_{2}$ (Fig. 6). A simplistic and chemically intuitive explanation for this number is that the average oxidation state $\left(\overline{\mathrm{OS}_{\mathrm{C}}}\right)$ of both isoprene and decane $\mathrm{C}$ atoms is $\sim-2$ and needs to increase to the value of +4 in $\mathrm{CO}_{2}$ at the end of the oxidation. $\mathrm{A}$ $\mathrm{C} 1$ unit reacting once with $\mathrm{OH}$ likely increases its $\overline{\mathrm{OS}_{\mathrm{C}}}$ by $\sim 2$. This increase is usually realized by an abstraction of $\mathrm{H}$ atom by $\mathrm{OH}$ or an addition of $\mathrm{OH}\left(\overline{\mathrm{OS}_{\mathrm{C}}}+1\right)$, followed by an abstraction of $\mathrm{H}$ atom by $\mathrm{O}_{2}$ or an addition of $\mathrm{O}_{2}\left(\overline{\mathrm{OS}_{\mathrm{C}}}+1\right)$. 


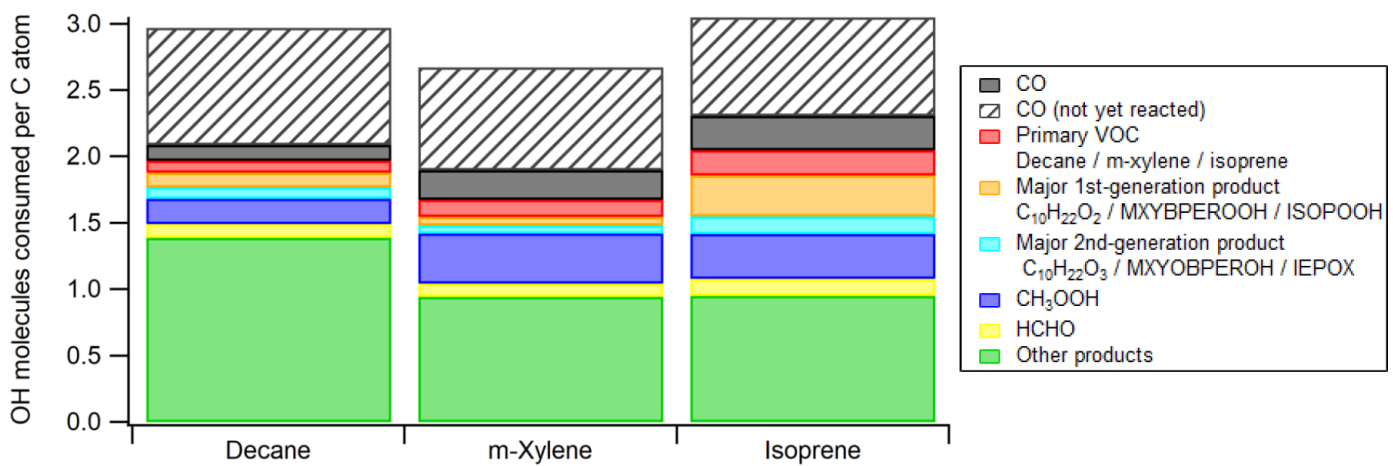

Figure 6. Average numbers of $\mathrm{OH}$ molecules consumed per $\mathrm{C}$ atom in the ambient cases with constant sunlight during photooxidation of isoprene, decane, and $m$-xylene. The contribution from $\mathrm{CO}$ that is not yet oxidized by $\mathrm{OH}$ at the end of simulation is also added to ensure that each $\mathrm{CO}$ molecule consumed one $\mathrm{OH}$ radical. ISOPOOH, IEPOX, $\mathrm{C}_{10} \mathrm{H}_{22} \mathrm{O}_{2}$, and $\mathrm{C}_{10} \mathrm{H}_{22} \mathrm{O}_{3}$ are isoprene hydroxyl hydroperoxides, isoprene epoxydiols, decyl hydroperoxides, and hydroxydecyl hydroperoxides, respectively. See Scheme S1 for the structures of MXYBPEROOH and MXYOBPEROH.

Note that $\sim 3 \mathrm{OH}$ consumed per $\mathrm{C}$ atom oxidized to $\mathrm{CO}_{2}$ is likely an upper limit, since the mechanisms in this study do not include $\mathrm{RO}_{2}$ autoxidation (Crounse et al., 2013; Ehn et al., 2014), which reduces the number of $\mathrm{OH}$ needed for complete VOC oxidation. Also, in a real low-NO environment, $\mathrm{NO}$ is still present in low concentrations and converts $\mathrm{RO}_{2}$ to RO. RO may undergo $\mathrm{H}$ abstraction through isomerization or reaction with $\mathrm{O}_{2}$, which also lowers the number of $\mathrm{OH}$ needed, although the effect is usually small. The number of $\mathrm{OH}$ consumed per $\mathrm{C}$ atom in $m$-xylene oxidation is slightly lower than three (Fig. 6) because of the multiple addition of $\mathrm{O}_{2}$ following a single $\mathrm{OH}$ addition in the initiation reaction, i.e., $m$-xylene $+\mathrm{OH}$.

\section{Summary and conclusions}

Using the fully explicit GECKO-A model, we simulated OHR evolution in the photooxidation of several types of VOCs (i.e., alkane, alkene, and aromatic) without NO until very high equivalent photochemical ages $(>10 \mathrm{~d})$ under a variety of conditions (in the atmosphere, chamber, and OFR). We analyzed the simulations in detail and found a number of common features as well as some differences resulting from certain precursors. These features are summarized below.

- All simulated non-methane cases very roughly follow this general oxidation chain pattern: precursor $\rightarrow$ first-generation products $\rightarrow$ (second-generation products $\rightarrow$ ) multifunctional species $\rightarrow$ highly oxidized $\mathrm{C} 1$ and $\mathrm{C} 2$ species $\rightarrow \mathrm{CO}$ (or $\mathrm{HCOOH}) \rightarrow \mathrm{CO}_{2}$. These species are generally not at steady state and gain significance/predominance one after another in the entire course of oxidation. Simulation results suggest that fragmentation products are not formed in significant amounts until the late stage of the oxidation, which would be a key difference from studies of OHR evo- lution in high-NO VOC oxidation (Nakashima et al., 2012; Sato et al., 2017).

- In methane oxidation, the intermediates do not gain dominance in sequence. Instead, they simultaneously increase as the oxidation proceeds and then simultaneously decrease when the methane decay becomes significant. The OHR evolution in methane oxidation is close to the idealized steady-state chain model, as the reaction of methane with $\mathrm{OH}$ is orders of magnitude slower than those of its oxidation intermediates, which allows the intermediates to reach their steady state.

The following discussion refers to the non-methane cases.

- Where different types of species dominate $\mathrm{OHR}_{\mathrm{VOC}}$ in sequence, OHR VOC increases after the current dominant type converts to one with a higher average OHR per $\mathrm{C}$ atom, and vice versa. Photooxidations of alkanes and aromatics follow the increasing trend from precursor to saturated multifunctional species (via alkyl monohydroperoxides) and from precursor to unsaturated oxygenated species, respectively. The increase in aromatic oxidation is likely to be more significant, since unsaturated oxygenated species are more reactive than saturated multifunctional species. The conversions from multifunctional species to $\mathrm{CO}_{2}$ lead to a decay of $\mathrm{OHR}_{\mathrm{VOC}}$ in both alkane and aromatic photooxidations. OHR VOC $_{\text {in }}$ alkene photooxidation is likely to always drop rapidly during $\mathrm{C}=\mathrm{C}$ bond oxidation and more slowly afterwards.

- A relatively weak enhancement of OHR per C atom of a $\mathrm{C}$ atom with $-\mathrm{OOH}$ substitution can explain the large range spanned by the precursors and their intermediates/products in this study at low $\mathrm{OH}_{\text {exp }}$. Around an $\mathrm{OH}_{\text {exp }}$ of $3 \times 10^{11}$ molecules $\mathrm{cm}^{-3} \mathrm{~s}$, precursors are largely converted to saturated multifunctional species 
(e.g., by addition to $\mathrm{C}=\mathrm{C}$ bonds in unsaturated precursors and abstraction of $\mathrm{H}$ atoms in saturated precursors), and the reactive mixtures of those precursors thus have similar OHR per $\mathrm{C}$ atom. They then all follow the course: multifunctional species $\rightarrow$ highly oxidized $\mathrm{C} 1$ and $\mathrm{C} 2$ species $\rightarrow \mathrm{CO}$ (or $\mathrm{HCOOH}) \rightarrow \mathrm{CO}_{2}$ and show similar decays of OHR per $\mathrm{C}$ atom.

- In decane and isoprene oxidation, our simulations show that each $\mathrm{C}$ atom consumes at most around three $\mathrm{OH}$ molecules in the course of its oxidation to $\mathrm{CO}_{2}$. This can be simplistically explained as three occurrences of oxidation by $\mathrm{OH}$ that increase, by two each time, the $\overline{\mathrm{OS}_{\mathrm{C}}}$ of decane and isoprene $(\sim-2)$ to that of $\mathrm{CO}_{2}(+4)$. The total number of $\mathrm{OH}$ consumed by each $\mathrm{C}$ atom is likely to be lower when $\mathrm{RO}_{2}$ autoxidation can be included in the mechanism generation.

In general, the OHR evolution differences resulting from different precursors are larger than those due to different conditions. The difference in $\mathrm{OHR}_{\mathrm{VOC}}$ between the ambient cases with constant and diurnal sunlight is small. Nevertheless, physical conditions may still lead to significant differences, which are summarized below.

- In current chambers, gas-wall partitioning can be a prominent issue that causes substantial wall partitioning of certain OVOCs of lower volatility, depending on the chemical system under study. The clearest example in this study is the substantial wall losses of C10 multifunctional species from the gas phase in decane oxidation and hence the remarkably lowered OHRVOC peak height in the chamber simulation. The wall also preferentially absorbs more oxidized (and thus lowervolatility) species, which alters the functional composition of gas-phase multifunctional species. The wall can even serve as a source of multifunctional species at very high $\mathrm{OH}_{\text {exp }}$, when the gas-phase concentrations of those species are very low. The magnitude of the effects of wall partitioning also depends on the size of the precursor, with the oxidation of larger precursors in chambers suffering larger impacts of wall partitioning.

- The strong wall losses have important implications, as they can change our modeling results substantially. Systematic OVOC gas-particle-wall partitioning corrections must be made for low-NO oxidation chamber ex-

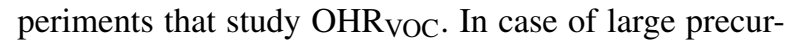
sors, highly chemically explicit modeling will likely be necessary to infer the OHR of multifunctional species, which may account for a large fraction of missing reactivity but suffer substantial wall losses. Although the few existing chamber studies on OHR ${ }_{V O C}$ evolution were all under high-NO conditions, which may result in more fragmentation and higher-volatility products, the magnitude of wall partitioning of large multifunctional species in this study is so substantial that we believe this effect would also be important at high NO. Schwantes et al. (2017) considered wall partitioning in their modeling of $o$-cresol oxidation based on MCM v3.3.1 but still could not achieve good agreement with the measurements for a number of products. Considering this, one should not assume that it is appropriate to neglect gasparticle-wall partitioning in high-NO chamber experiments, just based on agreement between the high-NO chamber experiments and modeling with MCM-based schemes and without gas-particle-wall partitioning corrections. Even for OHR studies with less surface loss issues, e.g., ambient studies, a combination of gas-phaseonly OHR measurement and modeling may still not be adequate as reduction of OHR due to OVOC condensation on aerosols can also be significant in some situations (Fig. S4). Therefore, condensed phases (particle and wall) need to be included in future OHR studies to better assess the deviation of the actual OHR from a purely gas-phase picture.

- OFR has two issues under certain conditions that can cause deviations from the ambient cases in terms of OHR VOC. Strong $\mathrm{RO}_{2}+\mathrm{OH}$ may significantly contribute to OHR VOC. Interestingly, this type of reaction does not seem to be able to substantially alter the composition of $\mathrm{OHR}_{\mathrm{VOC}}$ before the OHR $\mathrm{VOC}$ peak. Besides, the conditions resulting in strong water vapor photolysis have already been identified as those leading to atmospherically irrelevant $\mathrm{RO}_{2}$ chemistry in low-NO OFR in previous studies (Peng et al., 2019; Peng and Jimenez, 2020). As long as OFR users follow the guidelines for experimental planning provided in those studies (and use a much lower UV lamp setting), strong $\mathrm{RO}_{2}+\mathrm{OH}$ can be avoided, as shown in Fig. 1.

- The other main issue of OFR is the lack of efficient organic photolysis, particularly at high $\mathrm{OH}_{\text {exp }}$, when multifunctional species break into highly oxidized $\mathrm{C} 1$ and C2 compounds. This problem has been highlighted in previous studies (Peng et al., 2016; Peng and Jimenez, 2020) and been shown again in the present work to be extremely difficult to avoid if a high $\mathrm{OH}_{\text {exp }}$ is desired. However, the conversion of multifunctional species into highly oxidized $\mathrm{C} 1$ and $\mathrm{C} 2$ species may not be much slower in OFR than in the atmosphere, since $\mathrm{RO}_{2}+\mathrm{OH}$, leading to RO formation and subsequently its decomposition, may also play a major role in this conversion. This also results in significantly higher (lower) production of $\mathrm{HCHO}\left(\mathrm{CH}_{3} \mathrm{OOH}\right)$ in OFR than in the atmosphere at high equivalent ages.

With all the key findings in this study presented above, we believe that we have, to some extent, addressed the issues of missing reactivity, of model limitations, and of OHR in remote areas for OHR studies raised by Williams and Brune 
(2015). With the fully explicit GECKO-A model, we speciated the likely source of the missing reactivity, i.e., multifunctional OVOCs. A contrast between the technical issues in some isoprene and $m$-xylene simulations and the high consistency in the other cases highlights the importance of the completeness of the mechanism (even beyond the MCM level) in OHR-related modeling studies. Substantial wall partitioning of OVOCs in some chamber experiments highlights the importance of better constraining gas-to-surface deposition terms. More studies, both modeling (with highly chemically explicit mechanisms) and experimental (particularly low-NO), are needed to achieve better model-experiment closure. Finally, this study may have opened up the possibility of parameterizing the OHR evolution in (at least low-NO) VOC photooxidation as a function of $\mathrm{OH}_{\exp }$ only with the often-available knowledge on the first- and secondgeneration products and the relevant SARs such as Kwok and Atkinson (1995), as the OHR evolution beyond multifunctional species has been shown to be similar for most VOC oxidations. This parametrization may be utilized in regional and global models to better constrain OHR at high equivalent photochemical ages, e.g., in remote regions.

\section{Appendix A: The effect on $\mathrm{OH}$ reactivity of non-OH reactions in an $\mathbf{O H}-d r i v e n$ reaction chain}

1. Consider the following reaction chain, where $\mathrm{OH}$ is the only oxidant:

$$
\begin{array}{ll}
\mathrm{A}_{1}+\mathrm{OH} \rightarrow \mathrm{A}_{2}, & k_{1}, \\
\mathrm{~A}_{2}+\mathrm{OH} \rightarrow \mathrm{A}_{3}, & k_{2}, \\
\mathrm{~A}_{3}+\mathrm{OH} \rightarrow \mathrm{A}_{4}, & k_{3},
\end{array}
$$

etc.

At steady state, $k_{1}\left[\mathrm{~A}_{1}\right][\mathrm{OH}]=k_{2}\left[\mathrm{~A}_{2}\right][\mathrm{OH}]=k_{3}\left[\mathrm{~A}_{3}\right]$ $[\mathrm{OH}]=\ldots=C(C$ is a constant $)$.

Then OHR due to individual species, $\mathrm{OHR}_{i}$, is equal to $C /[\mathrm{OH}]$ and is identical for all species.

2. Consider a parallel conversion of $A_{1}$ to $A_{2}$ by a means other than reaction with $\mathrm{OH}$ :

$\mathrm{A}_{1}+\mathrm{OH} \rightarrow \mathrm{A}_{2}, \quad k_{1}$,

$\mathrm{A}_{1}+\mathrm{B} \rightarrow \mathrm{A}_{2}, \quad k_{1}^{\prime}, \mathrm{B} \neq \mathrm{OH}$.

At steady state, $k_{1}\left[\mathrm{~A}_{1}\right][\mathrm{OH}]+k_{1}^{\prime}\left[\mathrm{A}_{1}\right][\mathrm{B}]=C$.

Therefore, $\mathrm{OHR}_{\mathrm{A} 1}=k_{1}\left[\mathrm{~A}_{1}\right]<C /[\mathrm{OH}]$.

3. Now consider a reaction converting $A_{1}$ directly to $A_{3}$ occurring in parallel to reaction chain 1 :

$\mathrm{A}_{1}+\mathrm{D} \rightarrow \mathrm{A}_{3}, \quad k_{1}^{\prime \prime}, \mathrm{D} \neq \mathrm{OH}$,

$\mathrm{A}_{1}+\mathrm{OH} \rightarrow \mathrm{A}_{2}, \quad k_{1}$,

$\mathrm{A}_{2}+\mathrm{OH} \rightarrow \mathrm{A}_{3}, \quad k_{2}$.

At steady state, $k_{1}^{\prime \prime}\left[\mathrm{A}_{1}\right][\mathrm{D}]+k_{2}\left[\mathrm{~A}_{2}\right][\mathrm{OH}]=C$.
And $\mathrm{OHR}_{\mathrm{A} 1}<C /[\mathrm{OH}]$, since $k_{1}\left[\mathrm{~A}_{1}\right][\mathrm{OH}]=k_{2}\left[\mathrm{~A}_{2}\right]$ $[\mathrm{OH}]$.

Code and data availability. The chemical mechanisms generated and the outputs of the GECKO-A simulations in this study are available upon request.

Supplement. The supplement related to this article is available online at: https://doi.org/10.5194/acp-21-14649-2021-supplement.

Author contributions. ZP and JLJ conceived the study. ZP designed the study. JLT and ZP performed the simulations. HS, JLT, ZP, and JLJ developed the GECKO Loader and Plotter. ZP, JLT, JJO, and BA made updates and developments for GECKO-A. ZP, JLT, JJO, $\mathrm{BA}$, and JLJ analyzed the results. ZP led the manuscript writing with inputs from all authors.

Competing interests. The authors declare that they have no conflict of interest.

Disclaimer. Publisher's note: Copernicus Publications remains neutral with regard to jurisdictional claims in published maps and institutional affiliations.

Acknowledgements. We thank Sasha Madronich and Alma Hodzic for useful discussions. We would like to acknowledge high-performance computing support from Cheyenne (https://doi.org/10.5065/D6RX99HX) provided by NCAR's Computational and Information Systems Laboratory, sponsored by the National Science Foundation.

Financial support. This research has been supported by the National Science Foundation (grant nos. AGS-1822664 and AGS1740610).

Review statement. This paper was edited by Andreas Hofzumahaus and reviewed by two anonymous referees.

\section{References}

Atkinson, R. and Arey, J.: Atmospheric Degradation of Volatile Organic Compounds, Chem. Rev., 103, 4605-4638, https://doi.org/10.1021/cr0206420, 2003.

Aumont, B., Szopa, S., and Madronich, S.: Modelling the evolution of organic carbon during its gas-phase tropospheric oxidation: development of an explicit model based on a self generating approach, Atmos. Chem. Phys., 5, 2497-2517, https://doi.org/10.5194/acp-5-2497-2005, 2005. 
Ausloos, P. J. and Lias, S. G.: Photochemistry in the Far Ultraviolet, Annu. Rev. Phys. Chem., 22, 85-107, https://doi.org/10.1146/annurev.pc.22.100171.000505, 1971.

Bloss, C., Wagner, V., Jenkin, M. E., Volkamer, R., Bloss, W. J., Lee, J. D., Heard, D. E., Wirtz, K., Martin-Reviejo, M., Rea, G., Wenger, J. C., and Pilling, M. J.: Development of a detailed chemical mechanism (MCMv3.1) for the atmospheric oxidation of aromatic hydrocarbons, Atmos. Chem. Phys., 5, 641-664, https://doi.org/10.5194/acp-5-641-2005, 2005.

Brune, W. H.: The Chamber Wall Index for Gas-Wall Interactions in Atmospheric Environmental Enclosures, Environ. Sci. Technol., 53, 3645-3652, https://doi.org/10.1021/acs.est.8b06260, 2019.

Burkholder, J. B., Sander, S. P., Abbatt, J., Barker, J. R., Huie, R. E., Kolb, C. E., Kurylo, M. J., Orkin, V. L., Wilmouth, D. M., and Wine, P. H.: Chemical Kinetics and Photochemical Data for Use in Atmospheric Studies: Evaluation Number 18, JPL Publication 15-10, Pasadena, CA, USA, available at: http://jpldataeval.jpl.nasa.gov/ (last access: 1 July 2021), 2015.

Camredon, M., Aumont, B., Lee-Taylor, J., and Madronich, S.: The SOA/VOC/ $\mathrm{NO}_{\mathrm{x}}$ system: an explicit model of secondary organic aerosol formation, Atmos. Chem. Phys., 7, 5599-5610, https://doi.org/10.5194/acp-7-5599-2007, 2007.

Chameides, W., Lindsay, R., Richardson, J., and Kiang, C.: The role of biogenic hydrocarbons in urban photochemical smog: Atlanta as a case study, Science, 241, 1473-1475, https://doi.org/10.1126/science.3420404, 1988.

Cohen, A. J., Brauer, M., Burnett, R., Anderson, H. R., Frostad, J., Estep, K., Balakrishnan, K., Brunekreef, B., Dandona, L., Dandona, R., Feigin, V., Freedman, G., Hubbell, B., Jobling, A., Kan, H., Knibbs, L., Liu, Y., Martin, R., Morawska, L., Pope, C. A., Shin, H., Straif, K., Shaddick, G., Thomas, M., van Dingenen, R., van Donkelaar, A., Vos, T., Murray, C. J. L., and Forouzanfar, M. H.: Estimates and 25-year trends of the global burden of disease attributable to ambient air pollution: an analysis of data from the Global Burden of Diseases Study 2015, Lancet, 389, 1907-1918, https://doi.org/10.1016/S0140-6736(17)30505-6, 2017.

Crounse, J. D., Nielsen, L. B., Jørgensen, S., Kjaergaard, H. G., and Wennberg, P. O.: Autoxidation of organic compounds in the atmosphere, J. Phys. Chem. Lett., 4, 3513-3520, https://doi.org/10.1021/jz4019207, 2013.

Ehn, M., Thornton, J. A., Kleist, E., Sipilä, M., Junninen, H., Pullinen, I., Springer, M., Rubach, F., Tillmann, R., Lee, B., Lopez-Hilfiker, F., Andres, S., Acir, I.-H., Rissanen, M., Jokinen, T., Schobesberger, S., Kangasluoma, J., Kontkanen, J., Nieminen, T., Kurtén, T., Nielsen, L. B., Jørgensen, S., Kjaergaard, H. G., Canagaratna, M., Maso, M. D., Berndt, T., Petäjä, T., Wahner, A., Kerminen, V.-M., Kulmala, M., Worsnop, D. R., Wildt, J., and Mentel, T. F.: A large source of lowvolatility secondary organic aerosol, Nature, 506, 476-479, https://doi.org/10.1038/nature13032, 2014.

Fuchs, H., Hofzumahaus, A., Rohrer, F., Bohn, B., Brauers, T., Dorn, H. P., Haseler, R., Holland, F., Kaminski, M., Li, X., Lu, K., Nehr, S., Tillmann, R., Wegener, R., and Wahner, A.: Experimental evidence for efficient hydroxyl radical regeneration in isoprene oxidation, Nat. Geosci., 6, 1023-1026, https://doi.org/10.1038/Ngeo1964, 2013.

Fuchs, H., Novelli, A., Rolletter, M., Hofzumahaus, A., Pfannerstill, E. Y., Kessel, S., Edtbauer, A., Williams, J., Michoud, V., Du- santer, S., Locoge, N., Zannoni, N., Gros, V., Truong, F., SardaEsteve, R., Cryer, D. R., Brumby, C. A., Whalley, L. K., Stone, D., Seakins, P. W., Heard, D. E., Schoemaecker, C., Blocquet, M., Coudert, S., Batut, S., Fittschen, C., Thames, A. B., Brune, W. H., Ernest, C., Harder, H., Muller, J. B. A., Elste, T., Kubistin, D., Andres, S., Bohn, B., Hohaus, T., Holland, F., Li, X., Rohrer, F., Kiendler-Scharr, A., Tillmann, R., Wegener, R., Yu, Z., Zou, Q., and Wahner, A.: Comparison of $\mathrm{OH}$ reactivity measurements in the atmospheric simulation chamber SAPHIR, Atmos. Meas. Tech., 10, 4023-4053, https://doi.org/10.5194/amt10-4023-2017, 2017.

George, I. J. and Abbatt, J. P. D.: Heterogeneous oxidation of atmospheric aerosol particles by gas-phase radicals, Nat. Chem., 2, 713-22, https://doi.org/10.1038/nchem.806, 2010.

Haagen-Smit, A. J.: Chemistry and Physiology of Los Angeles Smog, Ind. Eng. Chem., 44, 1342-1346, https://doi.org/10.1021/ie50510a045, 1952.

Hallquist, M., Wenger, J. C., Baltensperger, U., Rudich, Y., Simpson, D., Claeys, M., Dommen, J., Donahue, N. M., George, C., Goldstein, A. H., Hamilton, J. F., Herrmann, H., Hoffmann, T., Iinuma, Y., Jang, M., Jenkin, M. E., Jimenez, J. L., Kiendler-Scharr, A., Maenhaut, W., McFiggans, G., Mentel, Th. F., Monod, A., Prévôt, A. S. H., Seinfeld, J. H., Surratt, J. D., Szmigielski, R., and Wildt, J.: The formation, properties and impact of secondary organic aerosol: current and emerging issues, Atmos. Chem. Phys., 9, 5155-5236, https://doi.org/10.5194/acp9-5155-2009, 2009.

Hodzic, A., Campuzano-Jost, P., Bian, H., Chin, M., Colarco, P. R., Day, D. A., Froyd, K. D., Heinold, B., Jo, D. S., Katich, J. M., Kodros, J. K., Nault, B. A., Pierce, J. R., Ray, E., Schacht, J., Schill, G. P., Schroder, J. C., Schwarz, J. P., Sueper, D. T., Tegen, I., Tilmes, S., Tsigaridis, K., Yu, P., and Jimenez, J. L.: Characterization of organic aerosol across the global remote troposphere: a comparison of ATom measurements and global chemistry models, Atmos. Chem. Phys., 20, 4607-4635, https://doi.org/10.5194/acp-20-4607-2020, 2020.

Isaacman-VanWertz, G. and Aumont, B.: Impact of organic molecular structure on the estimation of atmospherically relevant physicochemical parameters, Atmos. Chem. Phys., 21, 65416563, https://doi.org/10.5194/acp-21-6541-2021, 2021.

Jenkin, M. E., Saunders, S. M., Wagner, V., and Pilling, M. J.: Protocol for the development of the Master Chemical Mechanism, MCM v3 (Part B): tropospheric degradation of aromatic volatile organic compounds, Atmos. Chem. Phys., 3, 181-193, https://doi.org/10.5194/acp-3-181-2003, 2003.

Jenkin, M. E., Young, J. C., and Rickard, A. R.: The MCM v3.3.1 degradation scheme for isoprene, Atmos. Chem. Phys., 15, 11433-11459, https://doi.org/10.5194/acp-15-11433-2015, 2015.

Kang, E., Root, M. J., Toohey, D. W., and Brune, W. H.: Introducing the concept of Potential Aerosol Mass (PAM), Atmos. Chem. Phys., 7, 5727-5744, https://doi.org/10.5194/acp-7-5727-2007, 2007.

Keller-Rudek, H., Moortgat, G. K., Sander, R., and Sörensen, R.: The MPI-Mainz UV/VIS Spectral Atlas of Gaseous Molecules of Atmospheric Interest, available at: http://www. uv-vis-spectral-atlas-mainz.org (last access: 26 March 2019), 2020. 
Kovacs, T. A. and Brune, W. H.: Total OH loss rate measurement, J. Atmos. Chem., 39, 105-122, https://doi.org/10.1023/A:1010614113786, 2001.

Krechmer, J. E., Pagonis, D., Ziemann, P. J., and Jimenez, J. L.: Quantification of Gas-Wall Partitioning in Teflon Environmental Chambers Using Rapid Bursts of Low-Volatility Oxidized Species Generated in Situ, Environ. Sci. Technol., 50, 57575765, https://doi.org/10.1021/acs.est.6b00606, 2016.

Krechmer, J. E., Day, D. A., Ziemann, P. J., and Jimenez, J. L.: Direct Measurements of Gas/Particle Partitioning and Mass Accommodation Coefficients in Environmental Chambers, Environ. Sci. Technol., 51, 11867-11875, https://doi.org/10.1021/acs.est.7b02144, 2017.

Kwok, E. and Atkinson, R.: Estimation of hydroxyl radical reaction rate constants for gas-phase organic compounds using a structure-reactivity relationship: An update, Atmos. Environ., 29, 1685-1695, https://doi.org/10.1016/1352-2310(95)00069-B, 1995.

Lee-Taylor, J., Hodzic, A., Madronich, S., Aumont, B., Camredon, M., and Valorso, R.: Multiday production of condensing organic aerosol mass in urban and forest outflow, Atmos. Chem. Phys., 15, 595-615, https://doi.org/10.5194/acp-15-595-2015, 2015.

Levy II, H.: Normal atmosphere: large radical and formaldehyde concentrations predicted, Science, 173, 141-143, https://doi.org/10.1126/science.173.3992.141, 1971.

Li, R., Palm, B. B., Ortega, A. M., Hu, W., Peng, Z., Day, D. A., Knote, C., Brune, W. H., de Gouw, J., and Jimenez, J. L.: Modeling the radical chemistry in an Oxidation Flow Reactor (OFR): radical formation and recycling, sensitivities, and $\mathrm{OH}$ exposure estimation equation, J. Phys. Chem. A, 119, 4418-4432, https://doi.org/10.1021/jp509534k, 2015.

Liu, X., Day, D. A., Krechmer, J. E., Brown, W., Peng, Z., Ziemann, P. J., and Jimenez, J. L.: Direct measurements of semi-volatile organic compound dynamics show near-unity mass accommodation coefficients for diverse aerosols, Communications Chemistry, 2, 98, https://doi.org/10.1038/s42004-019-0200-x, 2019.

Lu, K. D., Hofzumahaus, A., Holland, F., Bohn, B., Brauers, T., Fuchs, H., Hu, M., Häseler, R., Kita, K., Kondo, Y., Li, X., Lou, S. R., Oebel, A., Shao, M., Zeng, L. M., Wahner, A., Zhu, T., Zhang, Y. H., and Rohrer, F.: Missing $\mathrm{OH}$ source in a suburban environment near Beijing: observed and modelled $\mathrm{OH}$ and $\mathrm{HO}_{2}$ concentrations in summer 2006, Atmos. Chem. Phys., 13, 10571080, https://doi.org/10.5194/acp-13-1057-2013, 2013.

Madronich, S. and Flocke, S.: The Role of Solar Radiation in Atmospheric Chemistry, in: Environmental Photochemistry. The Handbook of Environmental Chemistry (Reactions and Processes), vol 2/2L, edited by: Boule, P., Springer, Berlin, Heidelberg, pp. 1-26, 1999.

Mao, J., Ren, X., Brune, W. H., Olson, J. R., Crawford, J. H., Fried, A., Huey, L. G., Cohen, R. C., Heikes, B., Singh, H. B., Blake, D. R., Sachse, G. W., Diskin, G. S., Hall, S. R., and Shetter, R. E.: Airborne measurement of $\mathrm{OH}$ reactivity during INTEX-B, Atmos. Chem. Phys., 9, 163-173, https://doi.org/10.5194/acp-9163-2009, 2009.

Matsunaga, A. and Ziemann, P. J.: Gas-Wall Partitioning of Organic Compounds in a Teflon Film Chamber and Potential Effects on Reaction Product and Aerosol Yield Measurements, Aerosol Sci. Tech., 44, 881-892, https://doi.org/10.1080/02786826.2010.501044, 2010.
Mouchel-Vallon, C., Lee-Taylor, J., Hodzic, A., Artaxo, P., Aumont, B., Camredon, M., Gurarie, D., Jimenez, J.-L., Lenschow, D. H., Martin, S. T., Nascimento, J., Orlando, J. J., Palm, B. B., Shilling, J. E., Shrivastava, M., and Madronich, S.: Exploration of oxidative chemistry and secondary organic aerosol formation in the Amazon during the wet season: explicit modeling of the Manaus urban plume with GECKO-A, Atmos. Chem. Phys., 20, 59956014, https://doi.org/10.5194/acp-20-5995-2020, 2020.

Nakashima, Y., Tsurumaru, H., Imamura, T., Bejan, I., Wenger, J. C., and Kajii, Y.: Total $\mathrm{OH}$ reactivity measurements in laboratory studies of the photooxidation of isoprene, Atmos. Environ., 62, 243-247, https://doi.org/10.1016/j.atmosenv.2012.08.033, 2012.

Nannoolal, Y., Rarey, J., and Ramjugernath, D.: Estimation of pure component properties part 3. Estimation of the vapor pressure of non-electrolyte organic compounds via group contribution and group interactions, Fluid Phase Equilibr., 269, 117-133, https://doi.org/10.1016/j.fluid.2008.04.020, 2008.

Nehr, S., Bohn, B., Dorn, H.-P., Fuchs, H., Häseler, R., Hofzumahaus, A., Li, X., Rohrer, F., Tillmann, R., and Wahner, A.: Atmospheric photochemistry of aromatic hydrocarbons: $\mathrm{OH}$ budgets during SAPHIR chamber experiments, Atmos. Chem. Phys., 14, 6941-6952, https://doi.org/10.5194/acp-14-6941-2014, 2014.

Nel, A.: Air Pollution-Related Illness: Effects of Particles, Science, 308, 804-806, https://doi.org/10.1126/science.1108752, 2005.

Nguyen, T. B., Crounse, J. D., Schwantes, R. H., Teng, A. P., Bates, K. H., Zhang, X., St. Clair, J. M., Brune, W. H., Tyndall, G. S., Keutsch, F. N., Seinfeld, J. H., and Wennberg, P. O.: Overview of the Focused Isoprene eXperiment at the California Institute of Technology (FIXCIT): mechanistic chamber studies on the oxidation of biogenic compounds, Atmos. Chem. Phys., 14, 1353113549, 2014.

Nölscher, A. C., Butler, T., Auld, J., Veres, P., Muñoz, A., Taraborrelli, D., Vereecken, L., Lelieveld, J., and Williams, J.: Using total $\mathrm{OH}$ reactivity to assess isoprene photooxidation via measurement and model, Atmos. Environ., 89, 453-463, https://doi.org/10.1016/j.atmosenv.2014.02.024, 2014.

Nölscher, A. C., Yañez-Serrano, A. M., Wolff, S., de Araujo, A. C., Lavrič, J. V., Kesselmeier, J., and Williams, J.: Unexpected seasonality in quantity and composition of Amazon rainforest air reactivity, Nat. Commun., 7, 10383, https://doi.org/10.1038/ncomms10383, 2016.

Novelli, A., Kaminski, M., Rolletter, M., Acir, I.-H., Bohn, B., Dorn, H.-P., Li, X., Lutz, A., Nehr, S., Rohrer, F., Tillmann, R., Wegener, R., Holland, F., Hofzumahaus, A., KiendlerScharr, A., Wahner, A., and Fuchs, H.: Evaluation of $\mathrm{OH}$ and $\mathrm{HO}_{2}$ concentrations and their budgets during photooxidation of 2-methyl-3-butene-2-ol (MBO) in the atmospheric simulation chamber SAPHIR, Atmos. Chem. Phys., 18, 11409-11422, https://doi.org/10.5194/acp-18-11409-2018, 2018.

Orlando, J. J. and Tyndall, G. S.: Laboratory studies of organic peroxy radical chemistry: an overview with emphasis on recent issues of atmospheric significance, Chem. Soc. Rev., 41, 62946317, https://doi.org/10.1039/c2cs35166h, 2012.

Pankow, J. F. and Asher, W. E.: SIMPOL.1: a simple group contribution method for predicting vapor pressures and enthalpies of vaporization of multifunctional organic compounds, Atmos. Chem. Phys., 8, 2773-2796, https://doi.org/10.5194/acp-8-27732008, 2008. 
Peng, Z. and Jimenez, J. L.: Modeling of the chemistry in oxidation flow reactors with high initial NO, Atmos. Chem. Phys., 17, 11991-12010, https://doi.org/10.5194/acp-17-11991-2017, 2017.

Peng, Z. and Jimenez, J. L.: KinSim: A Research-Grade, UserFriendly, Visual Kinetics Simulator for Chemical-Kinetics and Environmental-Chemistry Teaching, J. Chem. Educ., 96, 806811, https://doi.org/10.1021/acs.jchemed.9b00033, 2019.

Peng, Z. and Jimenez, J. L.: Radical chemistry in oxidation flow reactors for atmospheric chemistry research, Chem. Soc. Rev., 49, 2570-2616, https://doi.org/10.1039/C9CS00766K, 2020.

Peng, Z., Day, D. A., Stark, H., Li, R., Lee-Taylor, J., Palm, B. B., Brune, W. H., and Jimenez, J. L.: $\mathrm{HO}_{\mathrm{x}}$ radical chemistry in oxidation flow reactors with low-pressure mercury lamps systematically examined by modeling, Atmos. Meas. Tech., 8, 4863-4890, https://doi.org/10.5194/amt-8-4863-2015, 2015.

Peng, Z., Day, D. A., Ortega, A. M., Palm, B. B., Hu, W., Stark, H., Li, R., Tsigaridis, K., Brune, W. H., and Jimenez, J. L.: Non-OH chemistry in oxidation flow reactors for the study of atmospheric chemistry systematically examined by modeling, Atmos. Chem. Phys., 16, 4283-4305, https://doi.org/10.5194/acp16-4283-2016, 2016.

Peng, Z., Palm, B. B., Day, D. A., Talukdar, R. K., Hu, W., Lambe, A. T., Brune, W. H., and Jimenez, J. L.: Model Evaluation of New Techniques for Maintaining High-NO Conditions in Oxidation Flow Reactors for the Study of OH-Initiated Atmospheric Chemistry, ACS Earth Space Chem., 2, 72-86, https://doi.org/10.1021/acsearthspacechem.7b00070, 2018.

Peng, Z., Lee-Taylor, J., Orlando, J. J., Tyndall, G. S., and Jimenez, J. L.: Organic peroxy radical chemistry in oxidation flow reactors and environmental chambers and their atmospheric relevance, Atmos. Chem. Phys., 19, 813-834, https://doi.org/10.5194/acp19-813-2019, 2019.

Rohrer, F., Bohn, B., Brauers, T., Brüning, D., Johnen, F.-J., Wahner, A., and Kleffmann, J.: Characterisation of the photolytic HONO-source in the atmosphere simulation chamber SAPHIR, Atmos. Chem. Phys., 5, 2189-2201, https://doi.org/10.5194/acp5-2189-2005, 2005.

Sato, K., Nakashima, Y., Morino, Y., Imamura, T., Kurokawa, J., and Kajii, Y.: Total $\mathrm{OH}$ reactivity measurements for the $\mathrm{OH}$-initiated oxidation of aromatic hydrocarbons in the presence of $\mathrm{NO}_{\mathrm{x}}$, Atmos. Environ., 171, 272-278, https://doi.org/10.1016/j.atmosenv.2017.10.036, 2017.

Schwantes, R. H., Schilling, K. A., McVay, R. C., Lignell, H., Coggon, M. M., Zhang, X., Wennberg, P. O., and Seinfeld, J. H.: Formation of highly oxygenated low-volatility products from cresol oxidation, Atmos. Chem. Phys., 17, 3453-3474, https://doi.org/10.5194/acp-17-3453-2017, 2017.

Siese, M., Becker, K. H., Brockmann, K. J., Geiger, H., Hofzumahaus, A., Holland, F., Mihelcic, D., and Wirtz, K.: Direct measurement of $\mathrm{OH}$ radicals from ozonolysis of selected alkenes: a EUPHORE simulation chamber study, Environ. Sci. Technol., 35, 4660-4667, 2001.

Stocker, T. F., Qin, D., Plattner, G.-K., Tignor, M., Allen, S. K., Boschung, J., Nauels, A., Xia, Y., Bex, V., and Midgley, P. M.: Climate Change 2013 - The Physical Science Basis, edited by: Intergovernmental Panel on Climate Change, Cambridge University Press, Cambridge, 2014.
Stone, D., Whalley, L. K., and Heard, D. E.: Tropospheric OH and $\mathrm{HO}_{2}$ radicals: field measurements and model comparisons, Chem. Soc. Rev., 41, 6348, https://doi.org/10.1039/c2cs35140d, 2012.

Turro, N. J., Ramamurthy, V., and Scaiano, J. C.: Principles of Molecular Photochemistry: An Introduction, University Science Books, Sausalito, CA, USA, available at: https://uscibooks.aip.org/books/ principles-of-molecular-photochemistry-an-introduction/ (last access: 25 January 2021), 2009.

US EPA: Estimation Programs Interface SuiteTM, available at: https://www.epa.gov/tsca-screening-tools/ epi-suitetm-estimation-program-interface (last access: 1 July 2021), 2012.

Valorso, R., Aumont, B., Camredon, M., Raventos-Duran, T., Mouchel-Vallon, C., Ng, N. L., Seinfeld, J. H., Lee-Taylor, J., and Madronich, S.: Explicit modelling of SOA formation from $\alpha$-pinene photooxidation: sensitivity to vapour pressure estimation, Atmos. Chem. Phys., 11, 6895-6910, https://doi.org/10.5194/acp-11-6895-2011, 2011.

Verwer, J. G.: Gauss-Seidel Iteration for Stiff ODES from Chemical Kinetics, SIAM J. Sci. Comput., 15, 1243-1250, https://doi.org/10.1137/0915076, 1994.

Verwer, J. G., Blom, J. G., van Loon, M., and Spee, E. J.: A comparison of stiff ODE solvers for atmospheric chemistry problems, Atmos. Environ., 30, 49-58, https://doi.org/10.1016/13522310(95)00283-5, 1996.

Wennberg, P. O., Bates, K. H., Crounse, J. D., Dodson, L. G., McVay, R. C., Mertens, L. A., Nguyen, T. B., Praske, E., Schwantes, R. H., Smarte, M. D., St Clair, J. M., Teng, A. P., Zhang, X., and Seinfeld, J. H.: Gas-Phase Reactions of Isoprene and Its Major Oxidation Products, Chem. Rev., 118, 3337-3390, https://doi.org/10.1021/acs.chemrev.7b00439, 2018.

Whalley, L. K., Stone, D., Bandy, B., Dunmore, R., Hamilton, J. F., Hopkins, J., Lee, J. D., Lewis, A. C., and Heard, D. E.: Atmospheric $\mathrm{OH}$ reactivity in central London: observations, model predictions and estimates of in situ ozone production, Atmos. Chem. Phys., 16, 2109-2122, https://doi.org/10.5194/acp16-2109-2016, 2016.

Williams, J. and Brune, W.: A roadmap for $\mathrm{OH}$ reactivity research, Atmos. Environ., 106, 371-372, https://doi.org/10.1016/j.atmosenv.2015.02.017, 2015.

Wofsy, S. C., Apel, E., Blake, D. R., Brock, C. A., Brune, W. H., Bui, T. P., Daube, B. C., Dibb, J. E., Diskin, G. S., Elkiins, J. W., Froyd, K., Hall, S. R., Hanisco, T. F., Huey, L. G., Jimenez, J. L., McKain, K., Montzka, S. A., Ryerson, T. B., Schwarz, J. P., Stephens, B. B., Weinzierl, B., and Wennberg, P.: ATom: Merged Atmospheric Chemistry, Trace Gases, and Aerosols, Oak Ridge National Laboratory Distributed Active Archive Center, Oak Ridge, Tennessee, USA, 2021.

Yang, Y., Shao, M., Wang, X., Nölscher, A. C., Kessel, S., Guenther, A., and Williams, J.: Towards a quantitative understanding of total OH reactivity: A review, Atmos. Environ., 134, 147-161, https://doi.org/10.1016/j.atmosenv.2016.03.010, 2016. 
Zannoni, N., Gros, V., Lanza, M., Sarda, R., Bonsang, B., Kalogridis, C., Preunkert, S., Legrand, M., Jambert, C., Boissard, C., and Lathiere, J.: OH reactivity and concentrations of biogenic volatile organic compounds in a Mediterranean forest of downy oak trees, Atmos. Chem. Phys., 16, 1619-1636, https://doi.org/10.5194/acp-16-1619-2016, 2016.
Ziemann, P. J. and Atkinson, R.: Kinetics, products, and mechanisms of secondary organic aerosol formation, Chem. Soc. Rev., 41, 6582-6605, https://doi.org/10.1039/c2cs35122f, 2012. 